\title{
THE DIGITIZATION OF PHOTOGRAPHIC ALBUMS AT THE VICTORIA AND ALBERT MUSEUM AND OTHER LONDON-BASED CULTURAL INSTITUTIONS
}

\author{
by \\ DAPHNE YUEN \\ Bachelor of Fine Arts, Ryerson University, 2014 \\ A thesis presented to Ryerson University \\ In partial fulfillment of the requirements \\ For the Degree of Master of Arts \\ In the Program of
}

Film and Photographic Preservation and Collections Management

Toronto, Ontario, Canada, 2017

(C) Daphne Yuen 2017 


\section{AUTHOR'S DECLARATION FOR ELECTRONIC SUBMISSION OF A THESIS}

I hereby declare that I am the sole author of this thesis. This is a true copy of the thesis, including any required final revisions, as accepted by my examiners.

I authorize Ryerson University to lend this thesis to other institutions or individuals for the purpose of scholarly research.

I further authorize Ryerson University to reproduce this thesis by photocopying or by other means, in total or in part, at the request of other institutions or individuals for the purpose of scholarly research. I understand that my thesis may be made electronically available to the public. 


\begin{abstract}
The Digitization of Photographic Albums at the Victoria and Albert Museum and Other London-based Cultural Institutions

Daphne Yuen

Master of Arts
\end{abstract}

Film and Photographic Preservation and Collections Management, Ryerson University 2017

This thesis investigates current digitization approaches to photographic albums by surveying the practices at the Victoria and Albert Museum in London, England alongside three other London-based institutions: the British Museum, British Library, and National Portrait Gallery. It highlights the value in researching and recording these documentation methods as an integral yet often overlooked part of museums' institutional history. For contextual background for the survey, a brief history of photographic albums and their inherent conservation issues is presented along with albums' digitization guidelines and a discussion of how digitization influences our relationship to the original object. The types of digitization methods employed at each institution is then examined to understand how curatorial and technical factors influence the digitization process and to observe the trends across the four institutions. A case study was performed at the Victoria and Albert Museum of a photographic album being digitized and is included in the Appendices. 


\section{ACKNOWLEDGEMENTS}

I would like to thank the numerous individuals who have assisted me in the research of this thesis by continually offering their time and support. This project would not have been conceivable without your generosity. At the Victoria and Albert Museum, I would like to thank Martin Barnes, Susanna Brown, Catherine Troiano, Briony Carlin, Erika Lederman, and Svenja Paulsen, who made up the incredible Photographs team that I worked with. Your constant encouragement and interest in my work helped to fuel my motivation and curiosity. Thank you to Richard Davis, Ken Jackson, and James Stevenson for offering their time to answer my endless questions about the V\&A Photo Studio, to Charlotte Hazeldine for allowing me to digitize my own guardbook, to Steve Woodhouse for sharing your VADAR expertise, to Richard Palmer for showing me the V\&A's future with IIIF, and to Jane Rutherston for teaching me about album handling and preservation.

I would also like to express my gratitude to Ivor Kerslake, Paul Gardner, and Kevin Lovelock from the British Museum, John Falconer, Alex White, Elizabeth Hunter, Neil McCowlen, and Carl Norman from the British Library, and Clare Freedman, Emma Cavalier, and Ed Lyon from the National Portrait Gallery. I am indebted to your assistance and contribution towards my research.

To my first reader Vid Ingelevics, for his enthusiasm and passion for the subject, I am tremendously grateful for your support and wisdom. I would also like to thank my second reader, Julienne Pascoe, for her specialized knowledge which was an invaluable asset to my thesis.

To my dad, family, and friends for their endless love and support throughout my Master's career and to Daniel Bodirsky for always believing in me. 


\title{
Table of Contents
}

\author{
ii Author's Declaration \\ iii Abstract \\ iv Acknowledgements \\ v Table of Contents \\ vi List of Figures \\ vii List of Appendices \\ 1 Introduction \\ $5 \quad$ Literature Survey \\ 13 Chapter One: Photographic Albums - A Short History and Introduction to Their \\ Preservation Issues \\ 18 Chapter Two: Reproductive Photography and Digitization within the Cultural Institution \\ 24 Chapter Three: Digitization of Photographic Albums at the Victoria and Albert Museum, \\ the British Museum, British Library, and National Portrait Gallery \\ 24 Structural Organization of Photographs at the Four Institutions \\ 26 Transition from Analogue to Digital Photography and Equipment \\ 28 The Functions of Each Institution's Photographic Studio and Their Digitization Initiatives \\ 32 V\&A Digitization Process for a Photographic Album \\ 32 Cataloguing Procedure for Photographic Albums at the V\&A \\ 36 Best Handling Practices and Evaluation of Photographic Album's Physical Condition \\ at the V\&A \\ 37 Methods of Digitizing Photographic Albums in the Photo Studio at the V\&A \\ 43 Digital and Online Presentation of Photographic Albums at the V\&A \\ 46 Conclusion \\ $50 \quad$ Appendices \\ 66 Bibliography
}




\section{List of Figures}

28 David Octavius Hill and Robert Adamson, Sir William Allan, calotype, 1843-1848, NPG P6(35)

29 Photograph of British Library's bespoke digitization book cradle

31 Photograph of British Museum's photography set-up for two-dimensional and copy work

31 Photograph of the De Vere 480 camera with scanning back

34 Kate E. Gough, Portrait of a woman writing at a desk, photo-collage, ca. 1870, 859-1963

35 Camille Silvy, Mrs. William Blackwell, albumen print, 15 May 1861, NPG Ax53059

38 Photograph of the Victoria and Albert Museum's photography set-up for guardbooks

39 Photograph of the Victoria and Albert Museum's custom-made book copy stand

39 Photograph of a close up of the Victoria and Albert Museum's book copy stand

41 Photograph of National Portrait Gallery's photography set-up for the Camille Silvy daybook

41 Photograph of British Library's photography set-up for bound volumes

42 Photograph of British Library's photography set-up to diffuse reflections and glare

44 Kate E. Gough, Artificial Flowers - Gibraltar (left) and England Expects Every Man to do His Duty (right), photo-collages, ca. 1870, 834-1963 and 835-1963 


\section{List of Appendices}

50 Appendix A - Digitization Practices Questionnaire

51 Appendix B - Technical Guidelines for Bound Volumes and Prints and Photographs from FADGI

53 Appendix C - Resolutions for Photographic Print Material from the National Archives of the Netherlands (Nationaal Archief)

54 Appendix D - Technical Information About the Photographic Studios at Four London-based Cultural Institutions

56 Appendix E - Case Study of the Digitization of a Guardbook at the Victoria \& Albert Museum 


\section{$\underline{\text { Introduction }}$}

Late nineteenth and early twentieth-century photographic albums have secured a place in museum collections due to increasing interest by historians in these objects' potential and role as cultural artifacts. Their artifactual status is informed by the original social context in which the album was constructed and is accentuated through its institutionalization. Photographic albums' current public function as cultural artifacts is further foregrounded when presented digitally or online by an institution. This increases these objects' accessibility for audiences and allows comparison of their contents with other objects. The digitization of an artifact allows its physical state to be recorded and preserved while producing a digital asset that can be used for a variety of digital and online platforms. The opportunities that are opened through digital imaging makes digitization essential to a museum's operations and mandate today. In addition, the digitization of photographic albums can itself be seen as historical and worthy of study as documentation methodologies are part of an institution's historical evolution, reflective of the time and conceptual understanding of such objects. As such they are a potential element of museology. ${ }^{1}$ Our preoccupation with the significance of the museum's collections has left the documentation process of those objects to be considered simply as a means to an end, resulting in a lack of institutional introspection regarding the histories of those practices.

A key responsibility of museums as custodians of historical objects is to exhibit their collections in new informative ways to promote engagement, enjoyment, and advancement of knowledge. For example, museums are starting to grant public access to high-resolution digital assets of their collections' objects as a result of an evolving understanding of the institution's role in society and to its community. This change in many museums' dissemination practices emphasizes their commitment to the access and

\footnotetext{
${ }^{1}$ Museology is the critical study of museum practices. A commonly accepted definition of museology in Western education was proposed by French museologist, Georges Henri Rivière in 1981: "Museology studies its history, its role in society, the specific forms of research and physical conservation, activities and dissemination, organisation and functioning, new or musealised architecture, sites that have been received or chosen, its typology and its deontology." (Desvalées and Mairesse, eds., ICOM Key Concepts of Museology, 54)
} 
research of its collections and demonstrates an awareness for their responsibilities as custodians of the public trust. Cultural thinking and understanding continue to change over time as a result of criticism and research by scholars, historians, and museums themselves. Consequently, a museum's understanding of its collection can also evolve, which can influence how objects are described and treated in catalogue records, in their digitization, and in their online presentation. For example, the museum photography of objects, has evolved over the years not just technically but also in terms of conceptual approach, embodied, for example, in a decision whether or not to crop a photograph from an album page, which influences the understanding of the final photographic product.

The photographic album, as defined for the purposes of this thesis, is a bound volume containing a number of leaves for the insertion or pasting of photographs. Since there are several types of albums that may house photographs, a photographic album can be distinguished from the others when it is comprised predominantly of photographs in proportion to other paper objects and ephemera. The album will have a handmade quality in its binding construction, text or in the attachment method of the photographic prints. While this definition may be applied to albums made in the twenty-first century, the objects to be considered here originate from the mid-nineteenth to the early twentieth centuries. The digital preservation of these objects is a priority since older photographic albums have suffered from more material deterioration over time. For that reason, these albums tend to be the focus of digitization in cultural institutions, although this does not exclude contemporary albums from undergoing the same treatment. Digital tools strive to render the album's narrative and sequential aspects as they are fundamental characteristics of the album.

In this thesis, in order to investigate current approaches to the digitization of photographic albums, the Victoria and Albert Museum is surveyed alongside the British Museum, the British Library, and the National Portrait Gallery. These four institutions have been selected because their collections 
contain photographic albums and they are influential cultural centres and international leaders in exhibition, education, and research. Of special interest, the V\&A's Photographic Studio is one of the oldest continuing studios in the world and has more recently undergone a transition from analogue to digital photography. The methodological approach for this survey took the form of informal interviews, discussions, and site visits with photographers from the museums' photographic studios. A questionnaire was devised to gather information regarding their album digitization practices (see Appendix A for the questionnaire). A practical case study of the digitization of a photographic album was carried out at the V\&A and is included in this paper's Appendices (see Appendix E).

A literature review was conducted to evaluate the existing research on the subjects of the history of photographic albums, digitization guidelines, and how digital forms can influence our relationship to cultural history. The intention of this review was also to both provide this thesis with a philosophical context and gain a sense of texts that provide practical solutions for museum professionals to address object materiality within the workflow of handling and digitizing a photographic album. 'Chapter One: Photographic Albums - A Short History and Introduction to Their Preservation Issues' will familiarize the reader with the thesis subject by presenting a short history of photographic albums, their inherent conservation issues, and why digitization is vital to their preservation. 'Chapter Two: Reproductive Photography and Digitization within the Cultural Institution' will then introduce digitization guidelines pertaining to photographic albums, the role of reproductive photography and digital media in museums, and touch upon how digitization influences our relationship to historical objects. 'Chapter Three: Digitization of Photographic Albums at the Victoria and Albert Museum, the British Museum, British Library, and National Portrait Gallery' will present an assessment of the collected data from the survey of the four London-based institutions in order to determine differences and similarities in practices. This chapter will also discuss and present examples of how curatorial decisions and concepts influence the 
digitization process and online presentation of a photographic album. Finally, the conclusion will summarize my findings from my survey and address further research opportunities in this field. 


\section{$\underline{\text { Literature Survey }}$}

The texts chosen for this literature survey are meant to provide a historical, theoretical, and practical context for the survey of current digitization approaches to photographic albums and have been published in the past ten years to ensure a degree of currency. They focus on the following subjects: photographic albums' social role in history; digitization's impact on the museum and object experience; and existing digitization standards for photographic albums.

\section{The Social History of the Photographic Album and its Role as Cultural Artifact}

Verna Posever Curtis’ Photographic Memory: The Album in the Age of Photography uses a number of examples to illustrate various contextual applications of the album format throughout the twentieth century. ${ }^{2}$ She provides an excellent material analysis by distinguishing the photographic album from its photographically-illustrated book counterpart by underlining its handcrafted construction, material, and design. The vital role that the intimate and performative encounter with an album plays in the interpretation of its content is also a fundamental concern in the digitization of photographic albums, making it an important consideration for this thesis. ${ }^{3}$ Although this text explores a wide scope of album types, it does not discuss their shift from once being private objects to cultural artifacts in the public realm, an examination that is central to the survey and discussion conducted in this thesis.

Martha Langford's Suspended Conversations discusses this shift of the document within the institution at greater length. ${ }^{4}$ She states that this move does not decontextualize the album but rather provides another lens through which to consider the object as a cultural and historical artifact. Her text studies how the ritualistic quality of albums and their basis in oral tradition has been interpreted once

\footnotetext{
${ }^{2}$ Verna Posever Curtis is the Curator of Prints and Photographs at the Library of Congress.

${ }^{3}$ Verna Posever Curtis, Photographic Memory: The Album in the Age of Photography (New York: Aperture Foundation, 2011)

${ }^{4}$ Martha Langford is an Associate Professor and Research Chair at Concordia University. 
housed in the institution. The digital extends this idea of the public, enabling cross-comparison and analysis, and expands the 'lens' through which to study photographic albums. ${ }^{5}$ For my thesis, it is important to understand the reason behind albums' initial entry into museum collections and to be conscious of the consequences of their subsequent digitization. My thesis acknowledges the philosophical implications of digitization while it primarily focuses on the technical aspects of the process for photographic albums. Digitization of an album also alters the physical experience, affecting the sense of object materiality, and consequently our interaction and relationship with the object.

Other examples of photographic album literature present a specialized study of certain types of albums. Elizabeth Siegel's Playing with Pictures: The Art of the Victorian Photocollage mainly concentrates on the history and analysis of photo-collage albums and that practice from mid to late nineteenth-century England. ${ }^{6}$ Siegel looks at how photo-collage compositions are reflections of the Victorian socio-political environment, how the album operated as a social device for relationships, and how they could be considered as a 'collective self-portrait' of female aristocrats in Victorian England. ${ }^{7}$ Playing with Pictures is a model of how photographic albums can be employed by scholars and institutions to gain an alternate perspective on British upper-class culture and society during the Victorian era. Siegel's text was helpful to this thesis in demonstrating how albums in particular can have a historical value worthy of academic study. The next series of considered texts address how our experience of the historical object has been altered in the age of digital media.

\footnotetext{
${ }^{5}$ Martha Langford and Musée McCord d'histoire canadienne, Suspended Conversations: The Afterlife of Memory in Photographic Albums (Montreal; Kingston: McGill-Queen's University Press, 2001)

${ }^{6}$ Elizabeth Siegel is the Associate Curator of Photography at the Art Institute of Chicago.

${ }^{7}$ Elizabeth Siegel, Playing with Pictures: The Art of Victorian Photocollage (Chicago: The Art Institute of Chicago, 2009), 13-30. 


\section{On Digitization's Impact on Object Materiality and Experience with Historical Objects}

Photographs Objects Histories: On the Materiality of Images, edited by Elizabeth Edwards and Janice Hart, contains essays from various individuals, most of whom have worked as museum professionals dealing with photography and exhibitions. ${ }^{8}$ This publication focuses on the importance of being sensitive to photographic materiality through acquiring a conscious understanding of photographs' ever-changing contexts arrived at by examining their use, role, and ownership. This is something that has often been overlooked to give priority to its content. ${ }^{9}$ Joanna Sassoon's "Photographic Materiality in the Age of Digital Reproduction" essay, in particular, offers a thorough theoretical look at the consequences of digitizing analogue photography by positing the untranslatability of the original. ${ }^{10}$ Sassoon's positive critique of how PictureAustralia presents its collection online through attempting to replicate the ordering systems from the material world helped me understand for this thesis how digital presentation is influenced by a museum's cataloguing procedure.

While Photographs Objects Histories highlights the importance of photographs' context and object materiality, Transforming Images: How Photography Complicates the Picture by Barbara Savedoff looks at how photography can alter the interpretation of its subject, especially of other art media. ${ }^{11}$ Savedoff's chapter 'Photographic Reproduction' speaks to the degree to which photographic reproductions are valued and used as true documents while not being completely successful in preserving aspects of their subject's texture, colour, lighting, framing, and physical presence. Savedoff argues that we have come to understand art through its photographically reproducible image meaning that the

\footnotetext{
${ }^{8}$ At the time of publication, Elizabeth Edwards was a Research Professor and Director of the Photographic History Research Centre in the UK while Janice Hart is the Head of Research at the London College of Communication in the UK and the MA course director in Photography: History and Culture.

${ }^{9}$ Elizabeth Edwards and Janice Hart, eds. Photographs, Objects, Histories - Introduction (Florence, US: Routledge, 2004), accessed 30 April 2017. ProQuest ebrary.

${ }^{10}$ Joanna Sassoon, "Photographic Materiality in the Age of Digital Reproduction" in Edwards and Hart, Photographs, Objects, Histories, 206, accessed 30 April 2017. ProQuest ebrary.

${ }^{11}$ Barbara Savedoff is an Associate Professor of Philosophy at Baruch College.
} 
reproduction is now the "paradigmatic art experience". ${ }^{12}$ Published in 2000, Transforming Images mainly addresses the photography of other art media and its section on 'Digital Reproduction' in Chapter 4 only begins to scratch the surface of how the digital impacts our relationship with cultural heritage.

Nonetheless, it presents important points to consider regarding how reproductive photography is produced as a 'transparent document', used and viewed differently from fine art photography. ${ }^{13}$ This text provided my thesis with a philosophical context and foundation upon which to consider the digitization of photographic albums.

The process of digitization complicates object materiality but it has also enabled different ways of thinking about the past, increasing analytical flexibility, and access to historical objects. Jenny Newell's essay “Old Objects, New Media: Historical Collections, Digitization and Affect” looks at how digitized objects in cultural institutions can transform people's relationship to history. ${ }^{14}$ Newell's piece is especially valued for the balance between a theoretical and practical exploration as she analyzes the digital construction and operation of Oscar's Scrapbook. ${ }^{15}$

The following two publications focus on how digitization and its uses have come to influence people's relationship with history. Digital Heritage and Culture: Strategy and Implementation is comprised of a series of essays that set out to illustrate the current state of digital heritage and the new ways relationships can be fostered with cultural artifacts. ${ }^{16}$ Edited by Steven Wu and Herminia Din, this text examines the challenges associated with establishing digital heritage programs and presents examples

\footnotetext{
${ }^{12}$ Barbara Savedoff, Transforming Images: How Photography Complicates the Picture (Ithaca, London: Cornell University Press, 2000), 157.

${ }^{13}$ Ibid., 151-184.

${ }^{14}$ Jenny Newell, “Old Objects, New Media: Historical Collections, Digitization and Affect" Journal of Material Culture 17, no. 3 (2012): 287-306.

${ }^{15}$ Jenny Newell is the Manager of the East Pacific Collections at the Australian Museum. Oscar's Scrapbook is a historic sketchbook drawn by Oscar, an Aboriginal stockman, in the 1890s when he was 8 or 9 of a Queensland cattle station. An interactive digital surrogate was created for an exhibition of this scrapbook that presented the book's history and pages. (Newell, 2012, 292-3)

${ }^{16}$ Steven Wu and Herminia Din, eds. Digital Heritage and Culture: Strategy and Implementation (New Jersey: World Scientific, 2015)
} 
of working solutions. ${ }^{17}$ James Quo-Ping Lin's essay “IT-Enabled Innovative Services as a Museum Strategy: Experience of the National Palace Museum, Taipei, Taiwan" is of particular interest to this thesis as he speaks about how digital collections can enhance information and contribute to the museum's primary responsibilities to collect, exhibit, educate, and research.

In contrast to Wu and Din's text, Theorizing Digital Cultural Heritage: A Critical Discourse, edited by Fiona Cameron and Sarah Kenderdine, offers a theoretical discussion around the relationship between museums and digital heritage by including a combination of texts by practitioners and theorists in diverse disciplines. ${ }^{18}$ Essays like Andrea Witcomb's “The Materiality of Virtual Technologies" and Fiona Cameron's "Beyond the Cult of the Replicant" argue that digital media are objects in their own right and not inferior to the historical object. Similar to Digital Heritage and Culture, this book mostly addresses how the public engages with digital media within the museum space. Essentially, the discussions concerning digital media in enhancing visitor experience both online and on-site can be applied to an album's digital facsimile. ${ }^{19}$

While the texts in this section examine the effects that increasing presence of digitized facsimiles both online and in the museum space have on the materiality of historical objects, they present minimal consideration of practical guidelines or how to improve the process of digital presentation. Photographic albums are not addressed, which is interesting since the issue of materiality is also crucial to the interpretation of these objects. The following publications focus more fully on the technical process of digitization for photographic albums.

\footnotetext{
${ }^{17}$ Steven Wu has previously served on the National Heritage Board in Singapore and Herminia Din is an Associate Professor at the University of Alaska Anchorage, USA.

${ }^{18}$ Fiona Cameron is a Senior Research Fellow at the Institute of Culture and Society at the University of Western Sydney, and Sarah Kenderdine is the Coordinator of Special Projects at the Museum Victoria in Melbourne.

${ }^{19}$ Fiona Cameron and Sarah Kenderdine, eds. Theorizing Digital Cultural Heritage: A Critical Discourse (Cambridge: MIT Press, 2007)
} 


\section{Digitization Guidelines and Standards for Photographic Albums}

“Technical Guidelines for Digitizing Cultural Heritage Materials: Creation of Raster Image Files” presented by The Federal Agencies Digitization Guidelines Initiative (FADGI) provides information regarding technical recommendations for digitization. FADGI is a group formed in 2007 to define digitization methods, practices, and guidelines for historical content and to standardize these practices to enhance and encourage the exchange and collaboration of digital information across institutions. ${ }^{20}$ The benefit of FADGI's guidelines is that they are constantly being reviewed and updated in order to stay current with changing technologies. The technical guidelines focus on material that can be reproduced as still images and are meant to be informative, not prescriptive. While the guideline is thorough in the sense that it defines file formats, technical language, the limitations of its scope, equipment, and workflow overview, object specificity is not its strong point. There are different specifications for books and photographs, but how to approach the digitization of photographic albums can be unclear because these objects bridge both categories.

The World Digital Library was a project created by the U.S. Library of Congress with the assistance of UNESCO and libraries, archives, and museums internationally. Its mandate is to offer resources, promote intercultural understanding, and to help bridge the 'digital divide' between countries. ${ }^{21}$ It is one of the few standards I have discovered that has included 'albums' on its advising list among other volumes like books, pamphlets, and ephemera, in which the recommended resolution is 400 ppi or higher. $^{22}$ It is unclear when the Digital Image Standards was last updated, however. Similarly, the National Archives of the Netherlands has published a "Digitisation of Photographs Guideline" which was

\footnotetext{
${ }^{20}$ Thomas Rieger, “Technical Guidelines for Digitizing Cultural Heritage Materials: Creation of Raster Image Files.” Federal Agencies Digitization Guidelines Initiative, last modified September 2016, http://www.digitizationguidelines.gov/guidelines/FADGI_Still_Image_Tech_Guidelines_2016.pdf

21 “World Digital Library - Digital Image Standards” World Digital Library, accessed $1 \overline{3}$ Feb 2017 , http://project.wdl.org/standards/imagestandards.html

22 The standard resolution of 400 ppi or higher is important to mention because resolution for photographs in comparison to textbased documents is often much higher in order to reproduce an image's detail, tonality, and clarity.
} 
presented to various European heads of conservation by Liesbeth Keijser, who was the head of project preservation and digitization of photographic materials for the Images for the Future project. ${ }^{23}$ This guideline suggests that album pages that are approximately 22 by 34 centimetres are to be scanned at 450 ppi. In addition, there is a brief statement advising individuals to take care in ensuring any text is still readable and to digitize the entire album page for context when necessary.

Digital Preservation for Libraries, Archives, and Museums by Edward Corrado and Heather Lea Moulaison examines the benefits of digitization for preservation and also provides an incredibly detailed overview of the digitization process, which doubles as a broad guideline. ${ }^{24}$ The text focuses on digital preservation in relation to copyright issues, future research, cost, technical specifications and content. ${ }^{25}$ The strengths of this text are its relevancy and its references to external resources. It does not outline specific requirements for types of cultural objects like the FADGI Guidelines, but I valued its lengthy discussion on digital preservation, which is a key concept of the life cycle management of digital assets. An understanding of the fragility and preservation of digital assets is as equally important as the preservation of the historical object. Therefore, a digital preservation strategy must also be considered when managing digitization projects in order to prevent file inaccessibility due to damage or corruption.

The documents published by FADGI, World Digital Library, and the National Archives of the Netherlands gave insight into existing technical specifications for photographic albums but they did not address any practical methods or techniques in the process of digitization such as how to photographically deal with weak spines, glare removal or how to stabilize the album page during documentation. However, the texts considered here emphasized the need for a survey of cultural institutions in order to discover current and practical digitization approaches to these objects.

\footnotetext{
${ }^{23}$ Martin Berendse, "Digitisation of Photographic Materials" Nationaal Archief-Images for the Future, last modified September 2010, http://en.nationaalarchief.nl/sites/default/files/docs/guidelines_digitisation_photographic_materials_0.pdf

${ }^{24}$ Edward Corrado is the Associate Dean of Library Technology Planning and Policy at the University of Alabama and Heather Lea Moulaison is an Assistant Professor at the iSchool of the University of Missouri.

${ }^{25}$ Edward M. Corrado and Heather Lea Moulaison, Digital Preservation for Libraries, Archives, and Museums (Maryland: Rowman \& Littlefield, 2014)
} 
The literature survey I have undertaken of the three topics has simultaneously enriched my knowledge of my subject's historical and cultural purpose and highlighted the lack of publications on specific digitization approaches to photographic albums. The photographic album's digital transition into the public realm still needs to be examined, expanding on Langford's concept of the institutionalization of the album. The texts on digitization's influence on object materiality often present a wide range of examples, but none precisely deal with photographic albums. Since albums' performative and tactile qualities are important for their interpretation, it would seem that they would be key subjects to include in this kind of discussion. In addition, digitization techniques and standards bearing on the digitization of photographic albums require additional research. 


\section{Chapter One}

\section{Photographic Albums - A Short History and Introduction to Their Preservation Issues}

Photography's increasing democratization and technological advancement in the mid-nineteenth century led to a profusion of images in everyday life. New photographic processes were invented that required increasingly less exposure time, simpler preparation than predecessors, and resulted in an increasing number of users. Carte-de-visite photographs, which were small format albumen prints mounted on card, reached a height of popularity in the 1860 s. The public fervently amassed these photographs and the album quickly became one of the organizational solutions to store and curate collected photography. Within these albums, photographs could be sequenced and composed on the page according to the album maker's wishes. ${ }^{26}$

Photographic albums can be categorized into three types, according to William Welling's Collector's Guide to Nineteenth Century Photographs. ${ }^{27}$ Personal albums, created by amateurs for leisure, date back to the 1860 s with the emergence of albums tailored to house cartes-de-visite, tintypes, and cabinet cards with cut-out mount leaves and were the first examples of the family album. Second, there were specialty albums, made and presented specifically for social or political occasions. Although Welling does not specifically address the tourist or travel album, it could also be considered to be a part of the specialty genre. The travel album was a popular album type in the nineteenth century where tourists would purchase commercially available photographic scenes to assemble into a souvenir album that they would often personalize with handwritten captions. Lastly, official albums were commissioned by the government to present the documentation of assignments completed by the military, for example. These also included private albums ordered by royalty to depict their family and property. ${ }^{28}$

\footnotetext{
${ }^{26}$ Curtis, Photographic Memory: The Album in the Age of Photography, 8.

${ }^{27}$ William Welling, Collector's Guide to Nineteenth Century Photographs (New York: Macmillian Publishing Co., Inc., 1976)

${ }^{28}$ Ibid., 73.
} 
Photographic albums underwent constant development to match the evolution of photographic printing processes and consumers' needs. There was a demand for album designs to reflect the popular photographic formats of the time. The styles of albums became simultaneously more complex and easier to reproduce as technologies and new materials became available. ${ }^{29}$ The period between 1861 and 1865 saw a minimum of fifteen patents issued for photographic albums or for the modification of the popular method of collecting "cards". ${ }^{30}$ The variations in leaf style, material, and binding often indicate the period in which an album was constructed. The more elaborate the design and structure, the later the album is usually dated.

\section{Bryan Clarke's paper "Some Observations on the Development of Albums Containing} Photographs and Aspects of their Deterioration" surveyed the stylistic changes in popular album designs and formats from a collection of approximately 1,200 albums dating from the 1860 s to the 1990 s at the National Maritime Museum in London, England. ${ }^{31}$ Photographic albums were separated into two categories based on the attachment method of photographs: "slip-in" and "paste-down". These terms also defined the way albums evolved from the mid-nineteenth century into the early twentieth century based on leaf style. "Slip-in" albums were ones designed for certain photographic formats, like the carte-devisite. A single leaf would be constructed from two conjoined pieces of heavy weight paper and a window opening would be cut-out for the photograph. ${ }^{32}$ The advantage to this album style was that photographs could easily be rearranged since no adhesive was used. The design of the cut-out mounts also allowed photographs to rest slightly beneath the page reducing contact with the facing leaf and minimizing surface abrasion. ${ }^{33}$ "Paste-down" albums had blank pages, which would require the photographs to be adhered

\footnotetext{
${ }^{29}$ Jane Rutherston, "Victorian Album Structures" (Master's thesis, Victoria and Albert Museum, 1996), 16.

${ }^{30}$ Robert Taft, Photography and the American Scene - A Social History 1839-1889, (New York: Dover Publications, 1938$), 41$.

${ }^{31}$ Bryan Clarke, "Some Observations on the Development of Albums Containing Photographs and Aspects of their Deterioration" The Imperfect Image: Photographs their Past, Present and Future (London: Centre for Photographic Conservation, 1992), 69.

${ }^{32}$ Clarke, "Some Observations on the Development of Albums" 70.

${ }^{33}$ Rutherston, "Victorian Album Structures" 24.
} 
using an attachment method like starch paste or photo corners. It offered more flexibility allowing for various photographic formats to be pasted in a portrait or landscape orientation. ${ }^{34}$

Inexpensive and low quality materials were used for the construction of albums as they became more commercialized. Wire stitching was introduced in the 1850 s for the binding of cheaper albums and the use of wood pulp fibres in paper and binding emerged around the 1870s. Earlier albums with simpler designs seem to have survived better over the years, as later examples were composed of a mixture of poorer materials. ${ }^{35}$ Many albums experience deterioration as a result of material degradation and handling over the years. While the albums' exterior may suffer from this structural weakening, some consider photographic albums to be guarding the photographs from airborne pollutants. In contrast, others argue that albums promote photographic deterioration because the prints are kept in close contact to acidic papers, dyes and adhesives. ${ }^{36}$ The cockling of the pages and photographs can also occur over time allowing dust and other pollutants to slip through the ingress. ${ }^{37}$ As a result of the poor construction of cheap leather and raw wood pulp-made strawboard, late nineteenth-century photographic albums generally suffer the worst deterioration. ${ }^{38}$ For this reason the digitization of photographic albums and creation of digital facsimiles is one solution to reduce further degradation from handling while maintaining a degree of access to album contents.

In recent decades, there has been a surge of academic interest in personal photographic albums, from scholars like Geoffrey Batchen, and a reintegration of these objects' histories into a larger history of photography. Cultural anthropologists have primarily worked with family albums, recognizing that

\footnotetext{
${ }^{34}$ Clarke, "Some Observations on the Development of Albums" 70.

${ }^{35}$ Rutherston, "Victorian Album Structures" 35.

${ }^{36}$ Clarke, "Some Observations on the Development of Albums" 75-77.

${ }^{37}$ Cockling is a process that occurs in such materials as paper, paperboard, vellum, or cloth in which the material becomes wrinkled, puckered, warped, or rippled. ("Getty Art and Architecture Thesaurus Online”, Getty Research Institute, accessed 1 June 2017)

${ }^{38}$ Clarke, "Some Observations on the Development of Albums" 75-77.
} 
sociological insight could be gained from their private narratives. ${ }^{39}$ The family album plays a role in the forming and shaping of collective memories within the domestic sphere. The photographs' compositions are informed by societal norms and constructs reflective of their time. These albums would have also functioned in public spaces as performative objects for the purpose of storytelling for guests, friends, and extended family. ${ }^{40}$ For this reason, they are both oral and visual mediums, offering clues to album cultures and customs as well as photographic practices of a particular time. ${ }^{41}$ As a result, museums have collected photographic albums for the objects' imbued cultural value and through this institutionalization the photographic album's primary function shifts from private to public realm. In the private sphere, the photographs act as a visual reminder for memories of family occasions and milestones that shape intricate personal narratives that may only be exclusively known to the family. Through a public lens, these photographs no longer just depict a birthday or wedding but are interpreted to be a part of a larger representation of domestic life and family identity. The album as social artifact allows for analyses of a period focused on class as well as place. Again, their situation in the public sphere is enhanced through digitization and the creation of digital facsimiles, increasing public accessibility and the potential interpretation of these objects.

The digitization of albums is fundamental to their physical preservation although the experience of their digital counterpart is not comparable to the original. Holding an album activates the ritual of storytelling, satisfying a collective desire to physically experience and be in close contact with the representation of human experience. The handling of albums over the years has resulted in their "patina of age and use' and enriches the pleasure and importance of viewing these objects in person. ${ }^{42}$ However, this also directly contributes to their deterioration. How can we present and translate the performative and sensory experience in digital form? While digital facsimiles are often viewed as inferior to the original,

\footnotetext{
${ }^{39}$ Mette Sandbye, "Looking at the family photo album: a resumed theoretical discussion of why and how" Journal of Aesthetics \& Culture 6, no. 1 (2014): 1-3.

40 Anna Dahlgren, "Dated Photographs: The Personal Photo Album as Visual and Textual Medium" Photography and Culture 3 , no. 2 (2010): 180.

${ }^{41}$ Ibid., 176.

${ }^{42}$ Curtis, Photographic Memory: The Album in the Age of Photography, 7.
} 
incapable of fully representing the artifact, they can offer an extended experience of the object, virtually connecting it to additional resources or cultural context. An example of the benefits of the digitization of photographic albums can be seen at the Library of Congress in Washington, D.C. They provide digital facsimiles to visiting researchers in place of the photographic albums that are particularly fragile. ${ }^{43}$ This strategy reduces the handling of the object whilst still offering access visually and informatively. Only under special circumstances, may the original be viewed by a researcher. Digital replicas may be the solution to minimizing further degradation but, ultimately, they do not offer the kind of tactile experience that we desire. Chapter Two will investigate in greater detail the use of reproductive photography prior to digitization, existing digitization guidelines for photographic albums, and finally, how the digital can revolutionize our experience of cultural artifacts.

\footnotetext{
43 “Albums of Photographs, 1850-present" The Library of Congress - Prints \& Photographs Reading Room, last modified December 2010, https://www.loc.gov/rr/print/coll/photoalbums.html 


\section{Chapter Two}

\section{$\underline{\text { Reproductive Photography and Digitization within the Cultural Institution }}$}

The founding director of the South Kensington Museum, Sir Henry Cole, recognized photography's reproductive capabilities for the purposes of access and education very early on. The Museum, which later became the Victoria and Albert Museum, was founded in 1852 based on the mandate of educating the public and inspiring British designers and manufacturers through training courses and the sharing of its collection, assembled to demonstrate key examples of art and design. The V\&A has the oldest continually-functioning photographic studio in the world, established in 1853. Charles Thurston Thompson was appointed its first Superintendent of Photography and photographed the Museum's collection, on-loan objects, and exhibitions. These images were then placed into large catalogue-albums called 'guardbooks' with the photographs made available for purchase by the general public and scholars (see Appendix E for images of a guardbook). ${ }^{44}$ The sale of these was a source of revenue that helped fund the operations of the Photographic Studio whilst offering a piece of the collection that the public could take home with them.

Similarly, Camille Silvy employed reproductive photography for the duplication of illuminated manuscripts and artworks in the 1860 s as his third career venture and in hopes it would inspire libraries to use photography in this manner. ${ }^{45}$ The Sforza Manuscript was purchased by Silvy to be photographed after the death of its owner, the ambassador of Sardinia-Piedmont to Britain. From the negatives, Silvy produced albumen prints that were printed on both sides in an attempt to mimic the manuscript's doublesided pages. The parchment provided a sufficiently bright background for the camera to pick up on the darker handwriting and Silvy lit the object to obtain black writing on a white background in his

\footnotetext{
${ }^{44}$ Guardbooks are large volumes that contain photographic prints that act as a visual inventory of the museum's collections and also represented the Photographic Studio's output. These guardbooks ran from 1853 to about 1994 when digitization was introduced at the V\&A led by James Stevenson, the former head of the Photographic Studio department.

${ }^{45}$ Camille Silvy (1834-1910) was a French photographer from an aristocratic family and worked mainly in London, England as an established portrait photographer. ("Search the Collection - Camille Silvy” National Portrait Gallery, accessed 1 June 2017) 
photographs. He noticed the sensitivity of the photographic chemical collodion to certain colours of the spectrum and claimed that the manuscript's faded handwriting was enhanced through the photographic process. He thus argued that photography could be employed for the restoration and reproduction of historical artifacts. Silvy's experiments with the Sforza manuscript may be the first instance of using photography to create a facsimile for scholarly purposes. Silvy had anticipated that with his facsimile example he could encourage libraries to share their respective manuscript collections with their colleagues, making original objects accessible for research beyond geographical limits. ${ }^{46}$

Stephen Bann cites Anne McCauley who argues that the newfound interest in reproductive and museum photography is a result of a general interest in the medium's early beginnings. This attention has brought work by photographers into focus who may have been previously overlooked, like Thurston Thompson. ${ }^{47}$ In his text, Art and the Early Photographic Album, Bann argues that the survival of particular photographic albums in the National Art Gallery's collection in Washington, D.C. are due to the value found in the photographically depicted works of art that these albums showcased. Bann states that while reproductive photography was never meant to be its own fine art, it served as a catalytic agent for the historical transformation of the art institution. Photography progressively became the best-suited medium for the documentation and representation of artworks. ${ }^{48}$

Nonetheless, the use and dissemination of reproductive photography should be done with a critical sensitivity. As Barbara Savedoff discusses in her book Transforming Images, photography alters its subject simply through the capturing process. While we rely on photography's accuracy of documentation, we must also be aware of its ability to mislead. Reproductive photography replicates the work of art as closely as possible without drawing attention to the medium of its documentation,

\footnotetext{
${ }^{46}$ Mark Haworth-Booth, "Camille Silvy: The Photography of Works of Art as Record and Restoration" in Bann, Art and the Early Photographic Album (New Haven: Yale University Press, 2011), 81-88.

${ }^{47}$ Stephen Bann, "Introduction" in Bann, Art and the Early Photographic Album, 3.

${ }^{48}$ Ibid., 12.
} 
photography. These subjects - Savedoff refers to art media in particular - are reduced to photography's transmittable qualities and we are encouraged to consider these reproductions as transparent documents. We regularly consider the original work in comparison to its reproduction since viewing the reproduction has become the paradigmatic experience of art. Juxtaposed against Walter Benjamin's famous claim that photography devalues the original artwork, Savedoff argues that reproductive photography has conditioned the way in which we respond to the original, if we encounter it at all. ${ }^{49}$

Today, the use of digitization in cultural institutions allows collection objects to be made available to an ever greater degree. The educational goals of the aforementioned examples of early reproductive photography are furthered through what is possible with digitization. Museums such as the Victoria and Albert Museum began to shift their photographic practices from analogue to digital technologies around the end of the twentieth century. The digital progressively replaced the need for expendable photographic film materials and developing chemicals, although early digitization equipment was costly and seen as a long-term investment for museums. Digitization programs became incorporated into museum missions as part of a larger mandate of access and preservation of cultural artifacts. Digital images online not only advertised the collection and attracted visitors to the museum but also increased revenue potential through the selling and licensing of images to external clients.

In the early 2000s, institutions like The Getty in Los Angeles and the Library of Congress in Washington, D.C. published literature on the subject of imaging and digital preservation to help guide cultural centres in project implementation. The Getty's Intro to Imaging summarizes the different aspects of the digitization process through a breakdown of equipment types, online resources, file management, and provides an overview of digital project planning considerations. In 2007, FADGI was formed as a collaboration between American federal agencies to create a set of technical guidelines and practices for the digitization of cultural material. Although they are based in the United States, FADGI's "Technical

\footnotetext{
${ }^{49}$ Savedoff, "Photographic Reproduction” 151-184.
} 
Guidelines for Digitizing Cultural Heritage Materials" are widely recognized not only for their precision but because they also are constantly reviewed and revised. The latest version was published in 2016 and addresses digitization and technical specifications for different types of objects, like bound volumes and photographs for example. These technical recommendations are categorized by the FADGI star system, from least to most recommended. This allows museums some flexibility in their digitization processes if they are not able to achieve the '4-star' level due to a lack of budget or resources. ${ }^{50}$

Technical specifications regarding photographic albums specifically can only be found in a relatively small number of sources. In FADGI's technical guidelines, photographic albums fall somewhere between the two categories, "Bound Volumes: Rare and Special Materials" and "Prints and Photographs", each advising a slightly different resolution requirement and colour accuracy parameter (see Appendix B). ${ }^{51}$ This minor discrepancy may not affect an individual album digitization project much, but could contribute to inconsistencies in practice by an institution over time or even between technicians.

Another example of technical recommendations for albums can be found within the "Digitisation of Photographic Materials" guideline published by the National Archives of the Netherlands for the use of technical and museum professionals (see Appendix C). This comprehensive guideline was a result of the Images for the Future project in 2010, one of the largest digitization programs in the cultural heritage field. ${ }^{52}$ It outlines the digitization workflow, handling recommendations, and software settings, similar to FADGI, but specifically for photographic material. It is therefore able to offer more specialized and detailed information regarding photography and photographic albums. A small section is even dedicated to the digitization of albums and photographs that are affixed to a cardboard mount. In these instances, it specifies that the digitization of the entire page may be necessary in order to provide context for the

\footnotetext{
${ }^{50}$ Rieger, "Technical Guidelines for Digitizing Cultural Heritage Materials: Creation of Raster Image Files"

${ }^{51}$ Ibid., 19-21, 34-36.

52 Berendse, "Digitisation of Photographic Materials"
} 
image. ${ }^{53}$ This is an interesting inclusion as it argues for the importance of contextual information in the digitization process, which subsequently informs its digital presentation as well. This is reflective of the weight given to object materiality in the past decade, changing the conceptual and even digital treatment of photographic albums and photographs. Returning to Savedoff, she argues for how reproductive photography transforms the work of art as she claims that the boundary of the image often coincides with the borders of the original work. ${ }^{54}$ Applying this idea to the digitization of photographic albums presents an interesting question: does the crop of a photograph versus the inclusion of the album's entire page signify what is considered to be the museum object? This question will be addressed once again in Chapter Three.

The application of digital media in cultural heritage has promoted a new way of understanding, using, and interpreting historical and cultural artifacts. ${ }^{55}$ Digital images are used for object records in internal collection management systems and museums' online databases, offering users a visualization of the collection and subsequently a better and faster tool for research. With the use of the IIIF platform (International Image Interoperability Framework), researchers are able to cross-analyze digitized objects from multiple institutions or to view the pages from a bound volume in varying sequences. ${ }^{56}$ Digitization has the ability to enhance an institution's primary responsibilities to acquire, present, educate, and research, which may be inhibited by an artifact's condition, a museum's physical space, or hours of operation. ${ }^{57}$ For many visitors today, a museum's website is their first point of contact with the institution rather than its galleries. Visitors' experience can be enriched by employing digital media within museum exhibitions and online. ${ }^{58}$ It can also be argued that while digital facsimiles can be

\footnotetext{
${ }^{53}$ Ibid., 22.

${ }^{54}$ Savedoff, "Photographic Reproduction" 152.

${ }^{55} \mathrm{Wu}$ and Din, eds. Digital Heritage and Culture: Strategy and Implementation (see note 16).

${ }^{56}$ The IIIF platform allows researchers to collect images from across institutions into online viewers. The V\&A has adopted the IIIF platform since 2009 and continues to employ it today. For more information on how they implement IIIF at the V\&A, visit - http://www.vam.ac.uk/blog/digital-media/iiif-at-the-va

${ }^{57}$ James Quo-Ping Lin, "IT-Enabled Innovative Services as a Museum Strategy: Experience of the National Palace Museum, Taipei, Taiwan" in Wu and Din, Digital Heritage and Culture (see note 16), 3-20.

${ }^{58}$ Christine Kuan, "7 Lessons Learned for Digital Culture" in Digital Heritage and Culture (see note 16), 41.
} 
socially engaging, they isolate the user because it eliminates the need for an intermediary, such as museum staff. ${ }^{59}$ Interaction with a human intermediary may provide an insightful experience in regards to the object or simply make more pleasurable the process of visiting the museum's reading room. This debate between virtual versus physical experience is central to how digitization and online presentation of photographic albums is approached. As Fiona Cameron discusses in her essay "Beyond the Cult of the Replicant", our conservative ideas of technology's role in cultural heritage are hindering the possibilities of digital media. In order to explore this potential, we must reconsider the relationship between historical artifact and its digital replica. ${ }^{60}$ Chapter Three will explore how the Victoria and Albert Museum and three other London-based cultural institutions deal with this relationship between the digital and analogue album/object through their practices of cataloguing, curation, digitization, and presentation.

\footnotetext{
${ }^{59}$ Ross Parry, Museums in the Digital Age (New York: Routledge. 2010), 237.

${ }^{60}$ Fiona Cameron, "Beyond the Cult of the Replicant: Museums and Historical Digital Objects - Traditional Concerns, New Discourses" in Theorizing Digital Cultural Heritage (see note 19), 49-70.
} 


\section{Chapter Three}

\section{Digitization of Photographic Albums at the Victoria and Albert Museum, the British Museum, British Library, and National Portrait Gallery}

This chapter draws information from the survey carried out at the Victoria and Albert Museum of its current approach to the digitization of photographic albums. The V\&A's practices are the main focus of this investigation but are presented in comparison to those of three other London-based cultural institutions: the British Museum, British Library, and National Portrait Gallery.

\section{Structural Organization of Photographs at the Four Institutions}

The V\&A founding mandate was centred around accessibility, education, and the inspiration of its public. As previously discussed in Chapter Two, Sir Henry Cole saw photography's potential for aiding these goals through the dissemination of the Museum's collection. The work by museum photographer Charles Thurston Thompson was once purely reproductive photography for documentation purposes but has also been elevated to the status of artwork in its own right. His tenure and photographs have proven essential to the understanding of the early years of the V\&A's institutional history. While he was the first of many photographers, Thurston Thompson takes on a particular importance because he was also a leading figure. No other museum photographer at the V\&A has yet to acquire the same level of prominence as Thurston Thompson. In parallel, Roger Fenton held a similar position at the British Museum but Fenton's fame was not primarily gained from his work at the museum but rather from his pioneering work during the Crimean War and in other fields of photography.

In the nineteenth century, photographs and photographic albums at the V\&A were initially cared for by the Museum's National Art Library. While photographs and photographic objects have been collected since the beginnings of the V\&A, it was not until 1977 that a distinct curatorial department for 
photographs was established. Photographs were transferred over to the newly formed Photographs Section, alongside Prints, Drawings, and Paintings. These objects that now form the basis of the Photographs Collection are not representative of the entirety of photographs that the V\&A holds, but rather were assembled for their significance to the medium's history. Photographic albums' literal shift in departmental location could perhaps also be understood as a conceptual shift in the way photography itself was perceived. Photographs were not simply documents but also potentially artifactual objects in their own right at the V\&A. In the late twentieth century, a similar emergence of Photography Departments can be found in various other cultural institutions. The National Portrait Gallery (NPG) for example, established their Photography Department in 1972, while other institutions, like the British Library (BL) and the British Museum (BM) hold photographic collections but do not have a separate Photographs Department. For some museums, these departments signified the start of actively collecting photography and/or the centralization of existing photographs that were previously spread across various departments.

Photographs at the BM and BL are collected and organized based on cultural content and context. The majority of this material at the BM can be found in the Anthropological and Oceanic Departments, while most of the BL's photographic collection is located in the Asia Department. The idea that photographs were documents at the BM did not exempt them from being re-photographed alongside other artifacts in their Photographic Studio, which was established in $1853 .{ }^{61}$ Perhaps even prior to 1977 , albums were re-photographed onto film as a means for sale, access, and exhibition. Similarly, photographic albums at the BL were also documented in its Photographic Studio, which was established a year after its separation from the BM in 1974.

\footnotetext{
${ }^{61}$ Similar to the V\&A, the BM established their Photographic Studio in 1853 but it was not continuously active since its formation. The studio ran until 1862 when Roger Fenton, the studio's first official photographer, retired from the position and was not replaced until 1927, when D. S. Lyon was employed. (Date and Hamber, "The Origins of Photography at the British Museum, 1839-1860” 319, 323)
} 


\section{Transition from Analogue to Digital Photography and Equipment}

The Photo Studio at the BM commenced its transition to digital in the early 2000 s. The COMPASS project that was launched in 2000 motivated the need for object digitization whilst also providing a platform to present digital images but it was stipulated that no new photography was to be produced. Instead, these initial digital files were high-resolution scans of pre-existing transparencies produced by a glassless scanner to reduce cost, time, and necessary resources. ${ }^{62}$ COMPASS was a website where visitors could map out their museum route according to the artifacts they wanted to see. Also around this time, the BM initiated a project funded by the Andrew Mellon Foundation to digitize the entirety of their Sir Aurel Stein collection. ${ }^{63}$ Mellon's vision was to digitally bring the painted works from the Stein collection together and hence sponsored the Museum's purchase of their first digital camera in $2004 .^{64}$

At the turn of the twenty-first century when both the V\&A and the BM adopted digital technology for their Photo Studios, the field was still emerging. In the early 2000s, there were few guidelines and resources to help direct cultural institutions in their digital practices. It was through continual experimentation and the sharing of knowledge that these London-based museum photographers established their own standardized practices. ${ }^{65}$ The Association for Fine Art and Historical Photography (AHFAP) was formed in 1985 in London by a national group of museum photographers to encourage dialogue between industry professionals. Since its founding, the group now has international membership and has held annual conferences each year to promote the exchange of specialized experience. ${ }^{66}$

\footnotetext{
${ }^{62}$ The scanner was a Cézanne Élite and the model is no longer in production.

${ }^{63}$ Sir Marc Aurel Stein was a British archaeologist who completed a series of expeditions to the western regions of China between 1900-1916. His collection is a result of those expeditions, including his archive, textiles, paintings, prints, and other three-dimensional artifacts. (Wang and Perkins, eds., Handbook to the Collections of Sir Aurel Stein in the UK, 40-47)

${ }^{64}$ Paul Gardner and Ivor Kerslake (former heads of the BM's Photo Studio), in conversation with the author, 11 April 2017.

${ }^{65}$ Ibid.

${ }^{66}$ Association for Historical and Fine Art Photography, accessed April 30, 2017, http://www.ahfap.org.uk/
} 
This organization has proven especially valuable for museums developing their photographic studios more recently, such as the NPG.

The NPG's Photo Studio was established in 2012 and the renovation to make it suitable for museum photography was generously funded by the Garfield Weston Foundation. Since the NPG's Photo Studio is relatively new, they seek advice from other industry experts and from organizations like AHFAP for the development of their studio and practices. At the NPG, photography is found in two collections, the Primary Collection and the Photographs collection. The digitization of objects is dictated by their status as Primary or Photographs collection objects. Primary collection objects, like the photograph of Sir William Allan by David Octavius Hill and Robert Adamson (Figure 3.1), are portraits of notable individuals who have contributed to British history and culture and are frequently requested due to popularity and status. ${ }^{67}$ These objects are therefore photographed with a complete colour checker and an uncropped, high-resolution version is saved in addition to its 'access file'. ${ }^{68}$ Objects from the Photographs collection are digitized with a greyscale card and only the edited file is retained. ${ }^{69}$

\footnotetext{
67 "Introduction to the Primary Collection" National Portrait Gallery, accessed 1 June 2017, http://www.npg.org.uk/collections/about/primary-collection/learn-more-primary

${ }^{68}$ An access file is a file that is often smaller in size to the master file, in a JPEG format.

${ }^{69}$ Emma Cavalier (Digitization Manager at the NPG), in conversation with the author, 3 April 2017.
} 


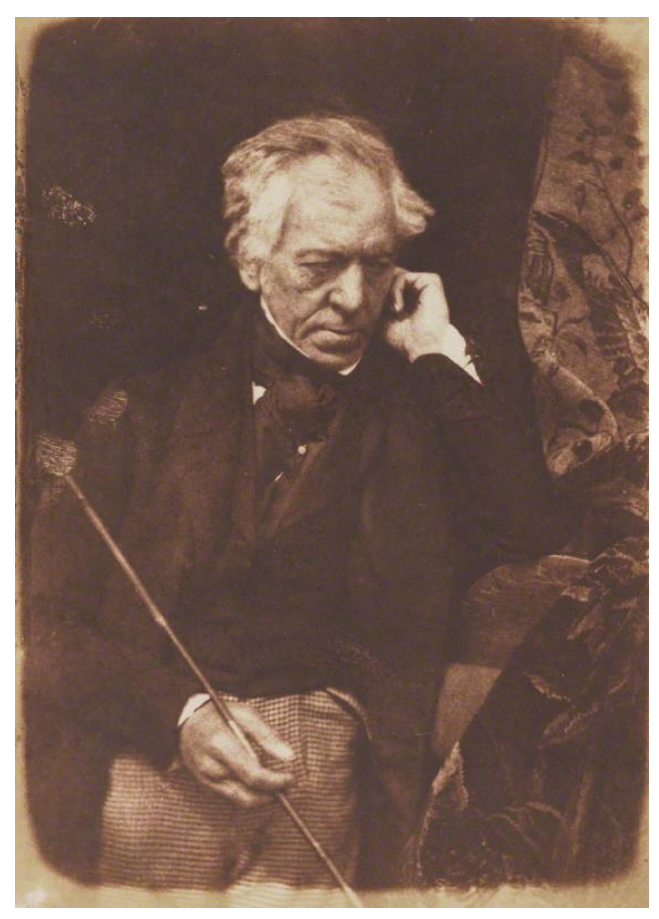

Figure 3.1 - Sir William Allan by David Octavius Hill and Robert Adamson, calotype, 1843-1848, NPG P6(35) (C) National Portrait Gallery, London.

\section{The Functions of Each Institution's Photographic Studio and Their Digitization Initiatives}

Each imaging studio operates slightly differently depending on their role within the institution. At the BL, the Photo Studio functions as a paid service for both internal and external imaging requests. The departments are required to pay for the digitization services and digital storage space since the studio is required to recover the cost of their service. Consequently, digitization of objects can only be done based on departmental budget and demand due to the number of requests the studio regularly receives. Objects are primarily photographed for research purposes, internal reference, and for publication. ${ }^{70}$

In comparison to the other cultural institutions included in this survey, the objects of digitization at the BL are different because its collection contains predominantly bound volumes that contain a number of textual pages. One volume involves a longer period of time and more separate shots to be

\footnotetext{
${ }^{70}$ John Falconer (Lead Curator of Prints, Drawings, and Photographs at the BL), in conversation with the author, 8 March 2017.
} 
completely digitized. Other museums, like the V\&A, that house a variety of three-dimensional artifacts in its collection often only need a small number of images to capture aspects of a single object. As a result, the digitization initiative at the BL is focused and prioritized based on 'celebrity' items that are more frequently requested. These differences in collections content have also influenced equipment acquisitions by each museum. The Photo Studio at the BL is comprised of eight photographers who produce highquality images, a bespoke book cradle used mainly for facsimile replicas, and scanners to reproduce images for reference research (Figure 3.2). ${ }^{71}$ Whereas, due to the BM's enormous collection of varied artifacts, there has been a division of photographic responsibilities based on object type.

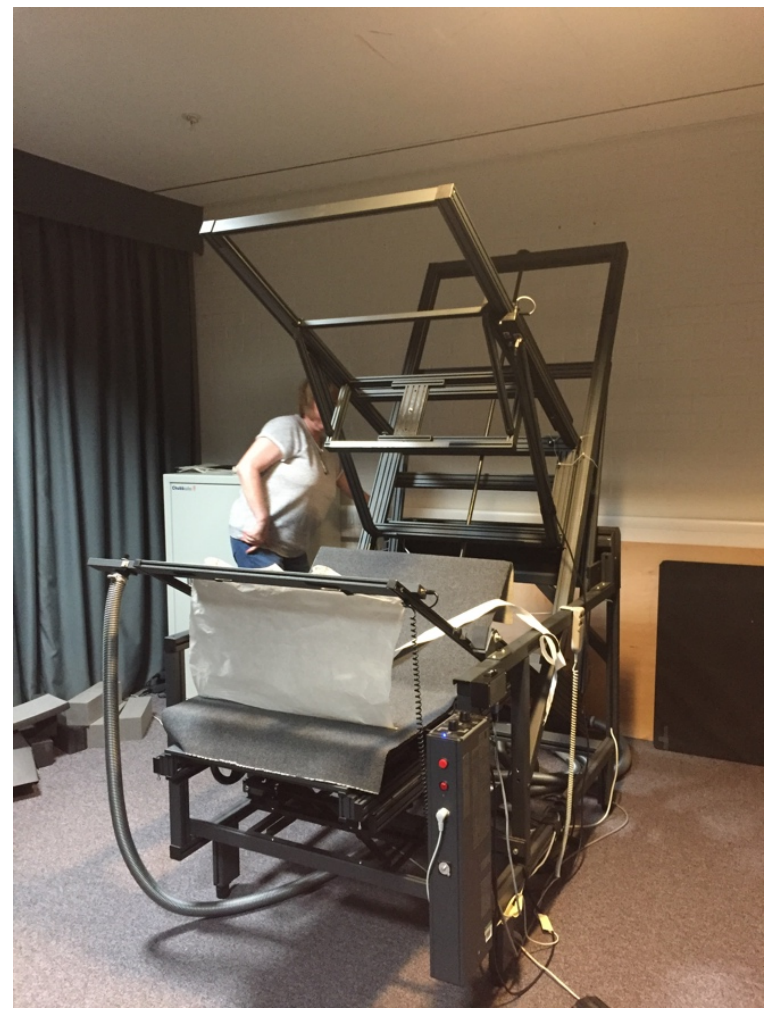

Figure 3.2 - Bespoke book cradle in the British Library photo studio, designed by Manfred Mayer from the University of Graz in Austria for the digitization of facsimiles. Photograph by the author.

\footnotetext{
${ }^{71}$ Alex White (Photographer at the BL), in conversation with the author, 19 April 2017.
} 
The responsibilities of the Photography and Imaging Department at the BM changed in 2007 as the result of a review of the studio's functions carried out by an external company, Phil Anderson \& Associates. It was recommended that better equipment and resources should be invested into the P\&I Department so that it could become more of an efficiently run, professional service, producing high quality images. A survey was carried out in consultation with internal and external parties, comprising over 50 individuals. Other institutions' photographic departments were visited such as the V\&A, Christie's Auction House and discussions were held with the Getty Picture Library, as well. Since then, the P\&I Department exclusively performs digitization for publications and for public requests, while record and condition images are done by departmental studios. These departmental studios are smaller and contain simpler equipment with the staff trained by the Photo Studio photographers. Products of the Photo Studio are consistently maintained in terms of colour-management and resolution, whereas the images produced by the departmental studios often vary. Photographic albums are regularly photographed within their own departments. If and when they are processed by the Photo Studio, albums are commonly scanned rather than photographed if they are in suitable condition. Otherwise, there is a set-up dedicated to two-dimensional work that uses an older PhaseOne system with a Powerphase FX scanning back, purchased originally for the digitization of the Stein collection around 1999 (Figure 3.3 and 3.4). The BM's overall digitization plan is not museum-wide due to the vastness of its collections, but is departmentally driven and decided by each department's keeper. ${ }^{72}$ While a majority of photographs and photographic albums are located in the Anthropological and Oceanic Departments, the Prints and Drawings Department has been the only section thus far to take on the challenge of digitizing their entire collection through scanning. ${ }^{73}$

\footnotetext{
${ }^{72}$ A keeper is a person who is the overseeing custodian or 'head' of a certain departmental or museum collection.

73 Kevin Lovelock (Senior Photographer at the BM), in conversation with the author, 12 April 2017.
} 

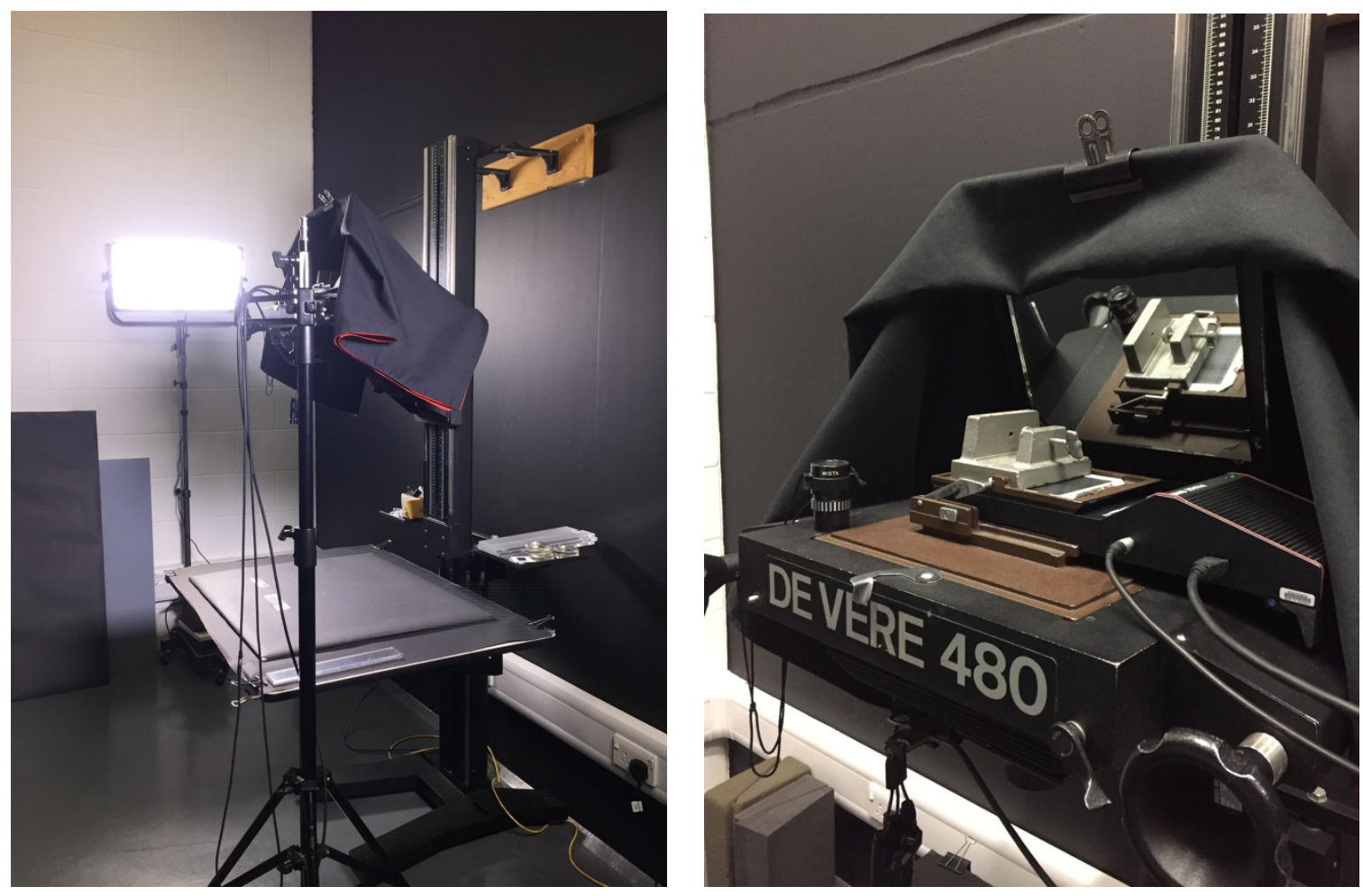

Figure 3.3 - Set-up at the British Museum dedicated to two-dimensional and copy work. Photograph by the author.

Figure 3.4 - A closer look at the De Vere 480 camera that has a scanning back. Photograph by the author.

Part of the overall digitization plan at the V\&A is the ongoing 'Factory Project'. This was a largescale initiative that was established in November 2007 to digitize and catalogue the entirety of the Word and Image (WID) collection that houses prints, drawings, paintings, and photographs. There are cataloguers and a photographer designated specifically to this project and each section within WID is granted one day every month to set forth new acquisitions to be digitized. The project was pursued to fulfill the Museum's mandate to increase public access to their holdings. Usually, the digitization workflow would require an object to have a catalogue record before it is digitized. The project was designed so that digitization and cataloguing could advance in parallel or individually from one another. ${ }^{74}$ An historic element that the V\&A is keenly interested in preserving through the Factory Project are past catalogue records of objects they are digitizing.

\footnotetext{
${ }^{74}$ Douglas Dodds and Ella Ravilious. "The Factory Project: digitisation at the Victoria and Albert Museum" Art Libraries Journal 34, no. 2. (2009): 10.
} 
The V\&A has three Photographic Studios with the largest one located in the main building of the museum. The second studio is located in the Henry Cole Wing, where it is largely reserved for the photography of two-dimensional objects and thirdly, at Blythe House Archives, where the V\&A's Archives are housed. All of the Photo Studios have standardized working methods, equipment, guidelines, and neutral-coloured environments in order to produce consistent results (see Appendix D for a full list of each institution's photographic studio specifications).

\section{V\&A Digitization Process for a Photographic Album}

The full process of digitizing a photographic album at the V\&A involves several steps and the participation of various departmental staff across the Museum. The album is subject to a preliminary and informal checklist including: establishing the purpose of digitization, verifying that catalogue records exist at the 'accessibility' level, and an evaluation of its physical condition. Parameters are established from these assessments for the digitization process. The catalogue record is a necessary requirement as it directly influences which elements of the album get digitized since digital assets must be linked to a corresponding record. This also explains why album covers were not previously photographed because there was no record for them to be attached to. In comparison, the first large project that the BL's Photo Studio received in 2010 required the digitization of photographic albums with the inclusion of cover, back, and spine. The addition of these album features to the digitization process has become the Library's template method of photographing albums since. ${ }^{75}$

\section{Cataloguing Procedure for Photographic Albums at the V\&A}

The V\&A has been redeveloping a cataloguing procedure for photographic albums that would make logical sense within their Collections Management System (CMS). Due to the V\&A's variety of

\footnotetext{
${ }^{75}$ Alex White (Photographer at the BL), in conversation with the author, 19 April 2017.
} 
collection objects, ranging from furniture and fashion to ceramics and 2-D art, CMS and its fields are custom designed by System Simulation Limited to be descriptively intricate to adapt to this diversity. ${ }^{76}$ As a result, it is difficult sometimes to adjust the description of photographs or photographic objects to the database content fields because they are often tailored to describe three-dimensional items with several parts. Contextual album aspects like the cover, binding, and end pages, did not have an exclusive catalogue record and were included as supplementary information to object records that described a photograph in the album. As previously noted, there has been an emerging interest in the past decade, however, in emphasizing object context and materiality, advocated by scholars such as Elizabeth Edwards. ${ }^{77}$ While the photographs within an album are still catalogued individually, they are now given a 'part number record' (E.100:1-2017, E.100:2-2017, etc.) as a part of the larger encompassing 'object root record' (E.100-2017), which is given to the album's external and supporting aspects. The description of these facets and any inscriptions found in these parts will belong to the root record. This approach also seems conceptually appropriate to cataloguing an album's parts as sub-records (inner contents) related to the main record (album's front and back covers). ${ }^{78}$

Inscriptions of Museum numbers can also contribute to the understanding of the object's history within the institution. The Museum's cataloguing and numbering systems evolve over time as a result of new working processes and technologies. For example, the V\&A's cataloguing method for all photographic objects has changed from the initial use of five digit numbers (12345), to the use of the prefix 'PH', and finally to 'E'. ${ }^{79}$ Instances of these older cataloguing standards can often be found written in pencil on the recto or verso of photographic objects (Figure 3.5 and 3.6).

\footnotetext{
${ }^{76}$ Dodds and Ravilious, "The Factory Project: digitisation at the Victoria and Albert Museum” 11.

${ }_{77}^{77}$ Edwards and Hart, eds. Photographs, Objects, Histories.

${ }^{78}$ Erika Lederman (Photographs Cataloguer at the V\&A), in conversation with the author, 27 February 2017.

${ }^{79}$ The prefix 'PH' was used from 1885 to 1908 , stopped from 1909 to 1977 , and was adopted once again in 1978 to 1987 . The prefix 'E' was then employed from 1987 until present day.
} 

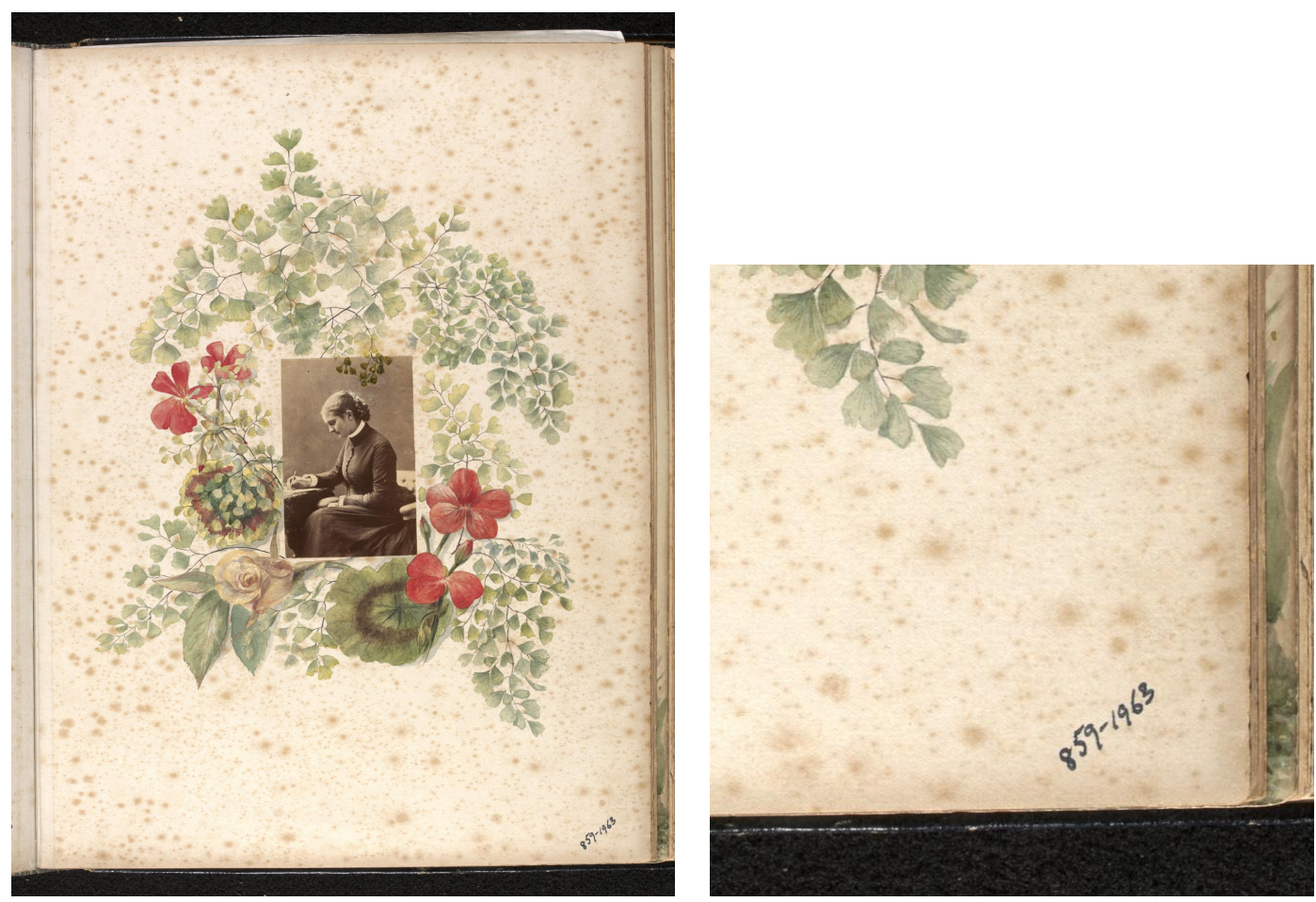

Figure 3.5 - Portrait of a woman writing at a desk by Kate E. Gough, albumen print and watercolour, ca. 1870, 859-1963. (C) Victoria and Albert Museum, London.

Figure 3.6 - Close up of the museum object number for Figure 3.5. (C) Victoria and Albert Museum, London.

In the case of the NPG, past examples of their museum numbering system can be found within their collection of Camille Silvy daybooks. ${ }^{80}$ Similarly to the V\&A, the NPG also allocates a unique museum number to every photograph within the album. Small albumen prints are organized into quadrants on each page where Silvy has assigned his own catalogue number and an NPG museum number (Figure 3.7). The photographed page is divided into four images in Photoshop so that each museum record will have a correlating digital asset. In the process of digitization, the Photographs curator has decided to have the NPG's pencil annotations digitally removed from the images because they are not part of the object's original history. ${ }^{81}$ This is an example of outdated cataloguing procedures that the gallery deems irrelevant and does not wish to be represented today. However, an argument can be made that these inscriptions could be interpreted as part of the album's history while under the custodianship of the

\footnotetext{
${ }^{80}$ There are twelve volumes of photographic albums called 'daybooks' that contain portraits of individuals and notable figures photographed by Camille Silvy and were digitized by the NPG from 2014 to 2016.

${ }^{81}$ Ed Lyon (Digitization Officer at the NPG), in conversation with the author, 25 April 2017.
} 
NPG and, therefore, part of a larger institutional history.

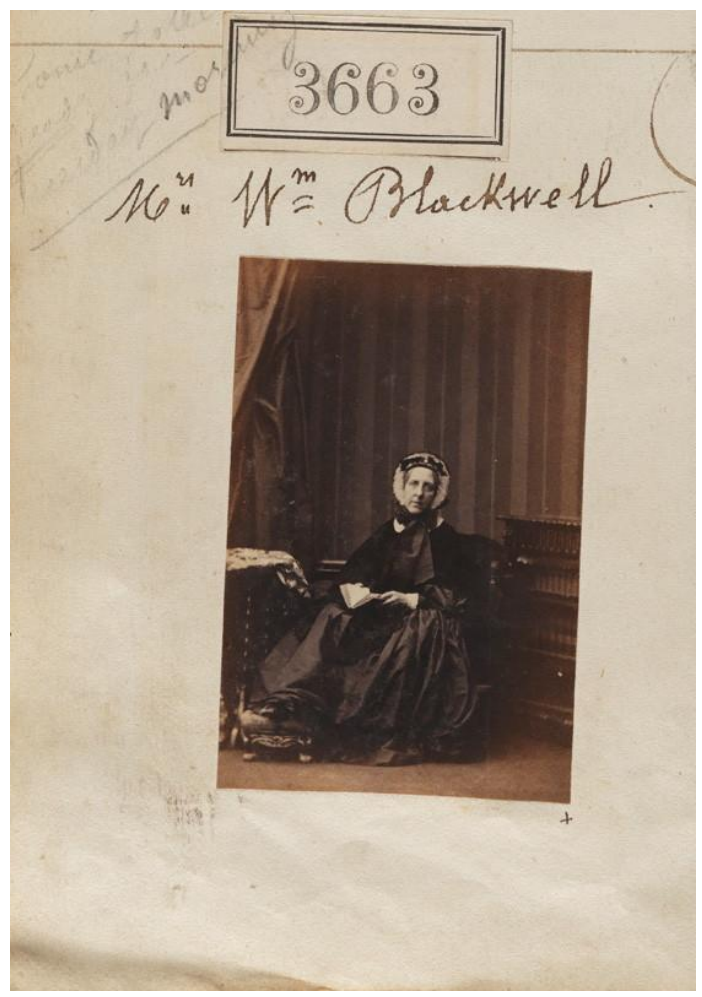

Figure 3.7 - Mrs. William Blackwell by Camille Silvy, albumen print, 15 May 1861, NPG Ax53059. (c) National Portrait Gallery, London.

The debate at the V\&A as to how albums should be reflected on CMS, is particularly complex when it comes to the Museum's cataloguing procedures and is also driven from a practical point of view. Albums have been historically catalogued according to the number of museum objects they contain, which means the number of photographs instead of the individual pages. Each photograph is given a distinguishable and therefore searchable object number. An assumption could be made then, that the photographic album is considered a vessel of multiple 'museum objects' rather than the photographs being the sum of a single museum object. An explanation could be that the way in which research is performed is often content and subject driven, especially online. It would therefore prove most useful for both the researcher and the institution to catalogue based on photographic content, particularly for photographic albums that contain multiple images. Another theory for this practice is that in the past loose 
prints that belonged together based on topic and photographer would often be bound together by the Museum itself. The prints would thus have existing museum object numbers before being grouped together in a volume. A third explanation is based on the removal of individual photographs from albums. Many albums in the collection do not contain pasted-in photographs, but easily removable cartes-de-visite or cabinet cards. One card might be removed from an album to be shown, framed, in an exhibition and therefore requires an individual number in order that its physical movements can be tracked separately.

\section{Best Handling Practices and Evaluation of Photographic Album's Physical Condition at the V\&A}

Before digitization, the physical condition of the photographic album is judged. Unless it is a unique case, this evaluation is often completed by the Photography curators. As noted earlier, albums are social and performative devices and often suffer deterioration from handling over the years. They are frequently stored on shelves, exposing them to dust accumulation on their top edge. The dust can then slip into the pages through an ingress created by the photographs' added thickness and cause damage to both page and image surface. The spines of albums are also weakened from overuse and from the volume being pulled off the shelf over the years. ${ }^{82}$ For these reasons, in addition to the conservation issues mentioned in Chapter Two, the digitization of photographic albums is vital to their long-term preservation and continuing accessibility.

It is also crucial to understand the best practices with which to handle these fragile bound volumes, especially for digitization, where an extended period of handling is required to photograph its contents. These handling limitations dictate the method of digitization, eventually establishing a general framework for the photographing of albums. The V\&A photographers are required to complete an object handling training course led by the Museum's Conservation Department so that they are well-versed in the handling of artifacts during the digitization process. For bound volumes, particularly oversized

\footnotetext{
${ }^{82}$ Jane Rutherston (Senior Book Conservator at the V\&A), in conversation with the author, 6 March 2017.
} 
objects, book cushions must always be used. An opening of $90^{\circ}$ to $110^{\circ}$ is sufficient for viewing an album and consequently, for digitizing. The page corner is often used to gently turn the pages but in some instances, this could also be the weakest point on the page due to the support leaves' brittle nature. The bottom edge or fore-edge would then be used depending on which one is the most stable. It is important not to run fingers across the page edge when supporting its weight because this will transfer dirt from one source to the rest of the page and it also risks touching the photographs. A thin tool like a bone folder can be used to assist in turning the pages, making it easier to slip under the leaves and provide immediate support for the page. At the V\&A, conservation has gradually become integrated into the digitization process, which was not previously the case. Photographic albums are always conserved before they are digitized unless they are being rebound, at which point then digitizing is possible while the leaves are still loose. $^{83}$

\section{Methods of Digitizing Photographic Albums in the Photo Studio at the V\&A}

After a 'photography requisition' is electronically submitted in CMS, the V\&A's Photo Studio receives detailed instructions on what needs to be photographed and how. During the digitization process, all major editing is done in-camera to keep post-production editing to a minimum. When an object or a page of an album is photographed, simple metadata is manually recorded within the digital file including the photographer's name, a 3-letter project code, object record number, and copyright status. The image's technical metadata is automatically assigned by the camera such as: file format, file size, bit-depth, and pixel dimensions. Once the object record number is attached to the image, the Digital Asset Management system, VADAR, automatically links the catalogue record information to the digital asset. ${ }^{84}$

\footnotetext{
${ }^{83}$ Ibid.

${ }^{84}$ Richard Davis (Head of the Photo Studio at the V\&A), in conversation with the author, 10 February 2017.
} 
The V\&A's Photo Studio approaches the digitization of photographic albums in three ways:

\section{$\underline{\text { Method \#1 }}$}

The first method, which is the most commonly used, is to have the album opened at an approximately $90^{\circ}$ angle with an overhead camera fastened to a copy stand (Figure 3.8). The album is propped up with a foam wedge and the recto of pages on the right hand side are photographed. The album is then rotated $180^{\circ}$ and the verso of the pages are photographed. This method is straightforward enough to rapidly digitize a bound volume, requiring minimal camera movement and handling. During the photographing process, the photographer checks the camera focus of the images every few pages to ensure accuracy and consistency. This is necessary because the distance between the lens and the album's page increases as the album is shot and the thickness of the remaining pages decreases, altering plane of focus. A guardbook was digitized as a case study using this method (see Appendix E). ${ }^{85}$

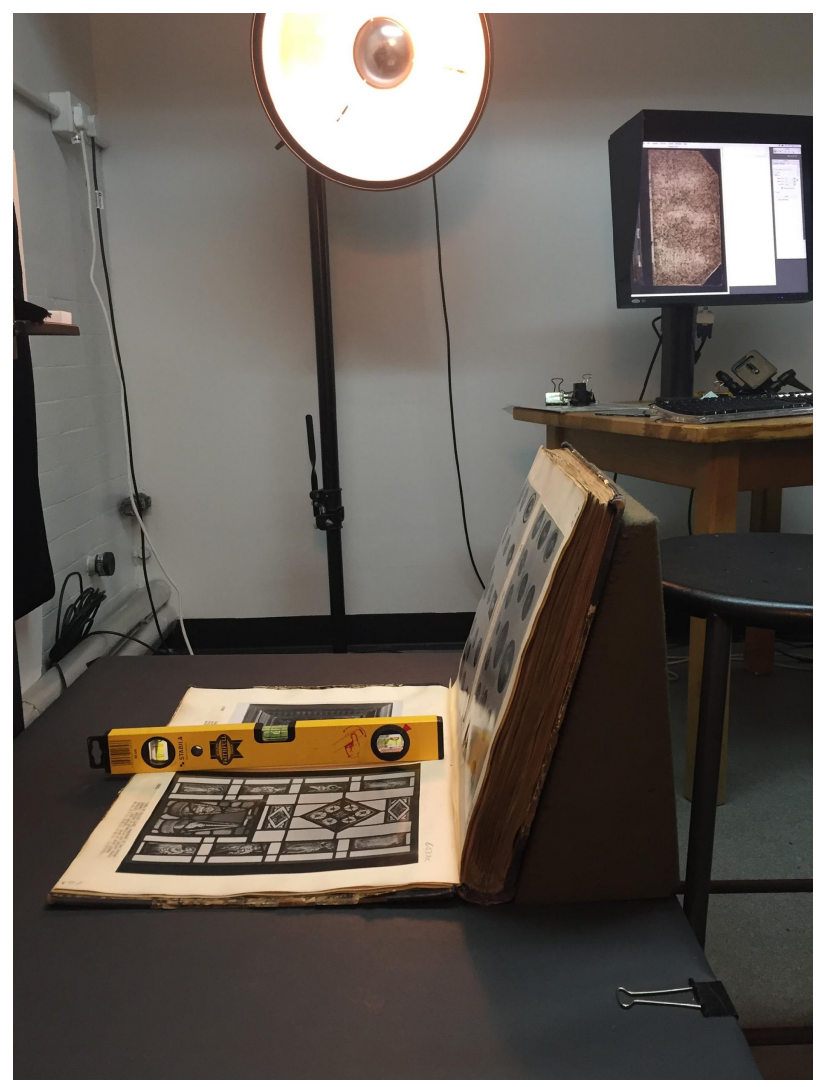

Figure 3.8 - V\&A's set-up at Blythe House Archives for the photographing of a guardbook using a large foam wedge. Photograph by the author.

${ }^{85}$ Ibid. 


\section{Method \#2}

The V\&A's second and sporadically used method is the custom-built book copy stand, which has been approved by the Books Conservation Department (Figure 3.9 and 3.10). The base of the stand is a platform that raises and lowers by moving its supportive wooden wedges in order to accommodate volumes of varying thicknesses. A glass plane hovers perpendicularly above the platform, held in place by two opposing pillars. One half of the volume slides through the gap between the base and glass and the other half lays flat against the glass, held in place with a Velcro strap. If a bound volume has a particularly weak spine this set-up is employed because it takes the strain off the binding. The advantage of this method is that it eliminates the need to check focal accuracy since the page sits flush against the glass. It is not used regularly, however, because it is a time-consuming process. Every time a page is turned, the volume needs to be unstrapped from the stand. ${ }^{86}$
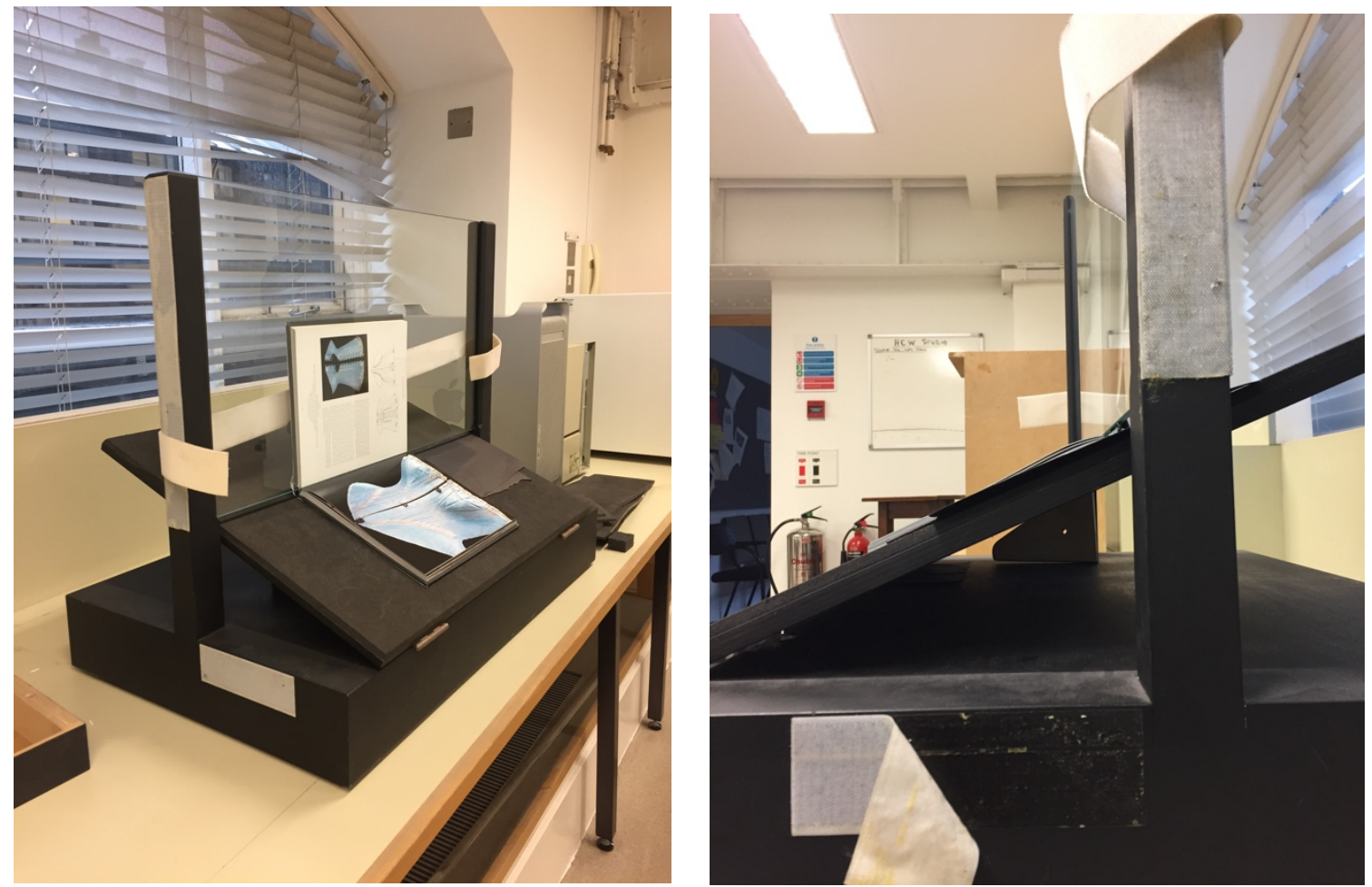

Figure 3.9 - V\&A's custom-made book copy stand that is used for photography of bound volumes that have a weak spine. The stand features a movable platform to accommodate volumes of different thicknesses and a Velcro strap to keep the side of the volume in place against the glass. Photograph by the author.

Figure 3.10 - A closer look at the wedge that controls the adjustment of the platform. Photograph by the author.

${ }^{86}$ Ibid. 
Method \#3

The last method called the 'surface silvered mirror' or 'front-surface mirror' was once in use at the V\&A but has now become obsolete. This approach was used to photograph leaves of albums that would not entirely open. The album page is reflected onto a mirrored surface, which is then photographed instead of the object itself. ${ }^{87}$ The BL has recently considered acquiring one of these devices precisely for the photographing of tightly bound volumes.

The standard method for digitizing photographic albums at the NPG, BM, and BL are similar to Method \#1 at the V\&A. At the BL, the set-up for photographic albums is identical to the digitization of other bound volumes, like manuscripts. Differences in approach can be found in the way the volume is held upright, but these methods are often interchangeable. The BL employs a Velcro strap while 'snake weights' are used by the NPG (Figure 3.11), BM, and occasionally the V\&A. In some instances, the album lays flat without assistance or is held in place by hand. The BL's set-up has been improved by one of its conservators to make it gentler on fragile volumes by using foam wedges. The assembly features two pieces of foam that are attached perpendicularly and a slight gap is left at the attachment point to accommodate the spine of volumes with a hollow back binding (Figure 3.12). ${ }^{88}$

\footnotetext{
${ }^{87}$ Ibid.

${ }^{88}$ Alex White (Photographer at the BL), in conversation with the author, 19 April 2017. 


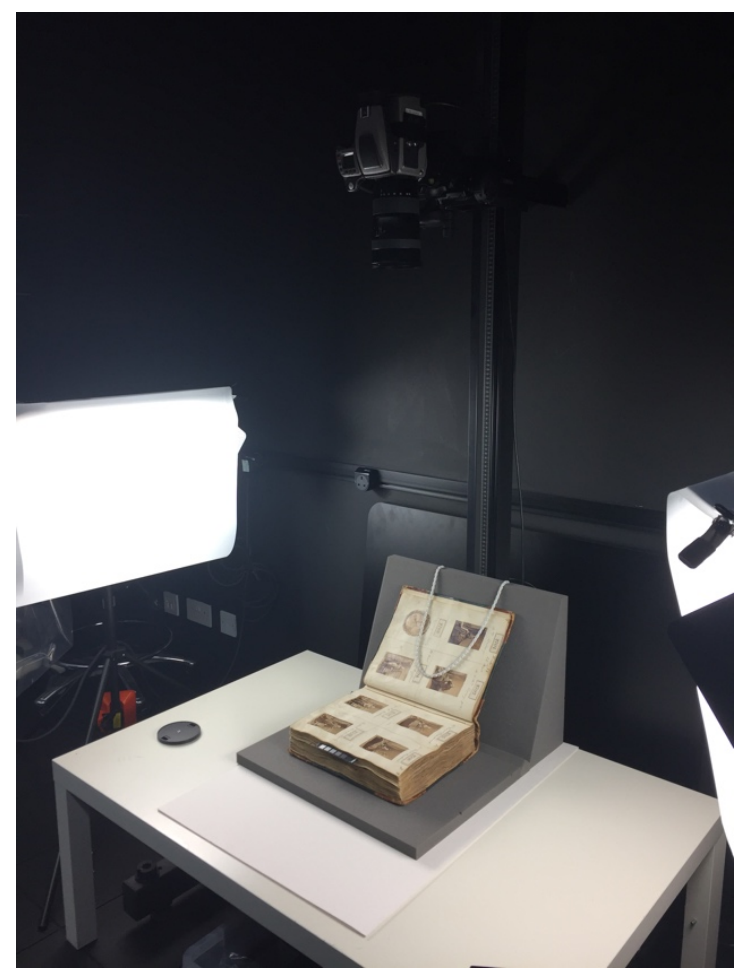

Figure 3.11 - National Portrait Gallery's set-up for the photography of a Camille Silvy daybook using a flat piece of foam, a foam wedge, and a snake weight. Photograph by the author.

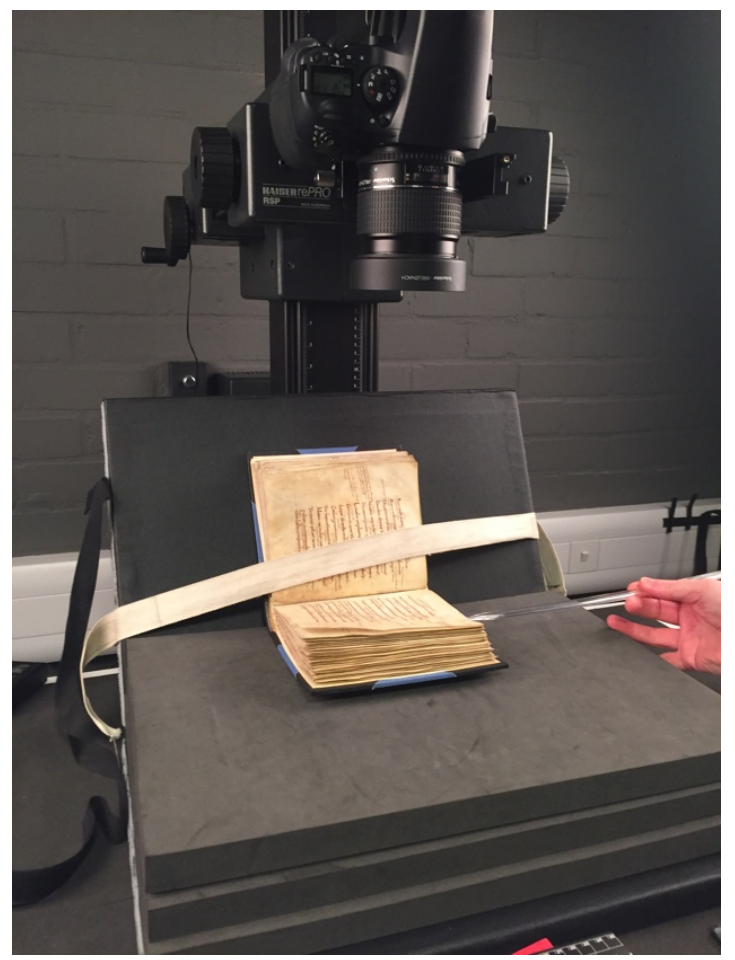

Figure 3.12 - British Library's set-up for the photography of a bound volume of manuscripts, using foam pieces, Velcro strap, and a glass wand to keep the pages flat. Photograph by the author. 
The standardization of photographic album digitization methods is limited to the general set-up that was first described because the needs of each album are always different. Aspects of the digitization set-up are slightly modified depending on the fragility of the binding or the finish of the photographs. For example, the BL recently completed a project in March 2017 for the British Film Institute where they digitized a series of photographic albums. Each album's photographs had a different finish (matte or glossy) and some suffered from excessive cockling and silver mirroring. ${ }^{89}$ These varying aspects necessitated for modification in the lighting set-up such as holding the pages down with a plastic wand or using special techniques counteract unwanted reflections and shadows in the images. For instance, to remove the glare in glossy photographs the strobe lights are diffused by directing them upwards at a black board or lowered to the same level as the album to reduce the shadows from the cockled pages. Another method is to have a rectangular piece of foam attached to the camera lens to deflect additional flare from the two opposing lights (Figure 3.13).$^{90}$ The approach to the digitization of photographic albums can only be regulated to a certain degree because what is photographed and how it is photographed is dependent on its final purpose.

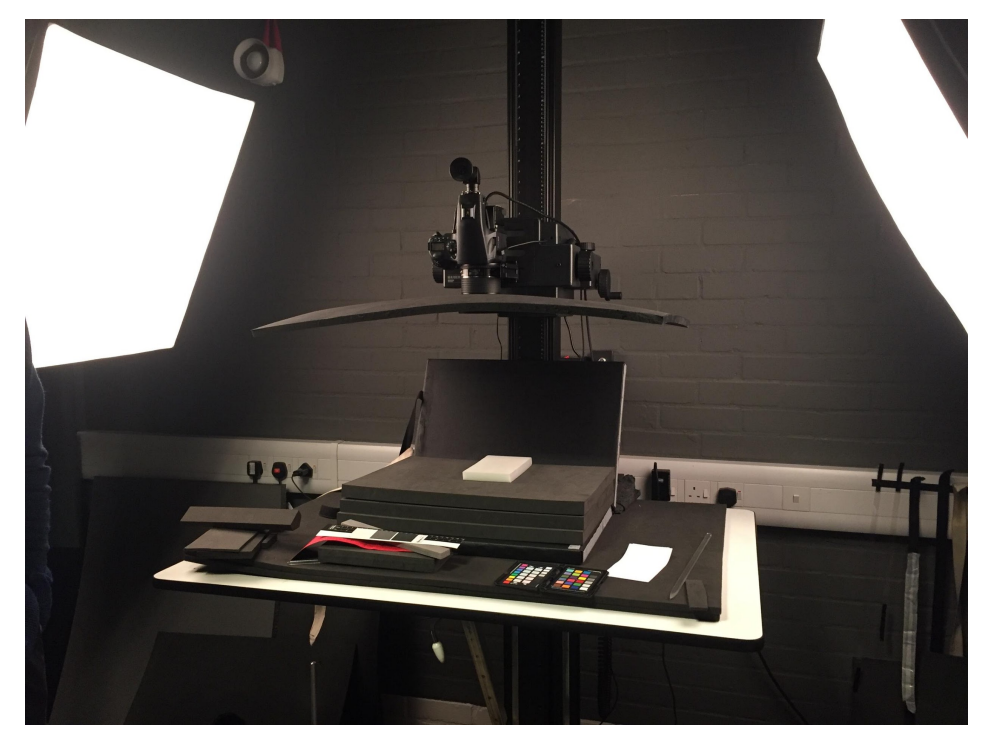

Figure 3.13 - The British Library's set-up for the photographing of photographic albums that contain photographs with a glossy finish. The piece of black foam is attached to the camera to counteract the reflection of the lighting in the photographs. Photograph by the author.

\footnotetext{
${ }^{89}$ Silver mirroring - oxidation of black-and-white images, in which the image silver migrates to the surface, creating a mirrorlike appearance. ("Image Permanence Institute Glossary" Image Permanence Institute, accessed 1 June 2017)

${ }^{90}$ Alex White (Photographer at the BL), in conversation with the author, 19 April 2017.
} 


\section{Digital and Online Presentation of Photographic Albums at the V\&A}

One of the main ambitions at the V\&A is to make their collection digitally accessible, which is why the Factory Project continues after ten years. The V\&A does not currently have most of its photographic album collection digitized and this only references items belonging to the Photographs Department. It is possible numerous others exist throughout the museum in other departmental collections. One of the primary purposes is to be able to have an image on the database for internal use and for the museum's online public database 'Search the Collections'. ${ }^{91}$ As part of this digitization initiative, interactive digital facsimiles will also be created for the website. These facsimiles will feature albums in a double-page view with the ability to virtually flip the pages and allow the photographs to be magnified. To create this album viewer, individual files of single pages are required so that each page can be manipulated independently and full resolution of the photographs is maintained. Since the photographs of these single pages cut off the album's fore-edge, the Photography curators were concerned about retaining object materiality. New double-page spread images were taken to portray the entirety of the object but ultimately could not be manipulated to the same degree as the previous files (Figure 3.14). Between the two options, a decision had to be made, and the curators opted for the 'page-turning' effect with maximum resolution. This simulation, created with the IIIF (International Image Interoperability Framework) platform, will ideally be presented alongside the album's records that allows the user the option to view the album's pages as a book.

IIIF is a significant initiative in terms of image interoperability within cultural heritage that aims to provide users with a high-level of access to image-based resources. ${ }^{92}$ It has influenced the way in which cultural institutions are publishing and sharing their digital content online and changing how researchers are able to consume, aggregate, and share these images. For example, users would be able to

\footnotetext{
${ }^{91}$ V\&A 'Search the Collections' online database - http://collections.vam.ac.uk/

92 “About IIIF" International Image Interoperability Framework, accessed 10 Aug 2017, http://iiif.io/about/
} 
bring together various copies of the same photograph from different museums into a digital viewer for cross-analysis. The move towards image interoperability illustrates an understanding of the informational value of digitized collection images and its importance to research and interpretation. The potentials of IIIF underscores the increasing necessity to digitize museum collections, encourages collaboration among institutions, and illustrates the benefits to providing open access to digital content. Using IIIF, the V\&A's interface will soon be able to produce files of different resolution types as per the user's request. The V\&A's DAM system, VADAR, currently does not have the ability to store structural data like the sequence of album pages in a field that is machine-readable. Therefore, this impacts how the images can be displayed online. The upcoming migration to the new DAM system, Aetopia, will hopefully resolve this issue of sequencing images. ${ }^{93}$

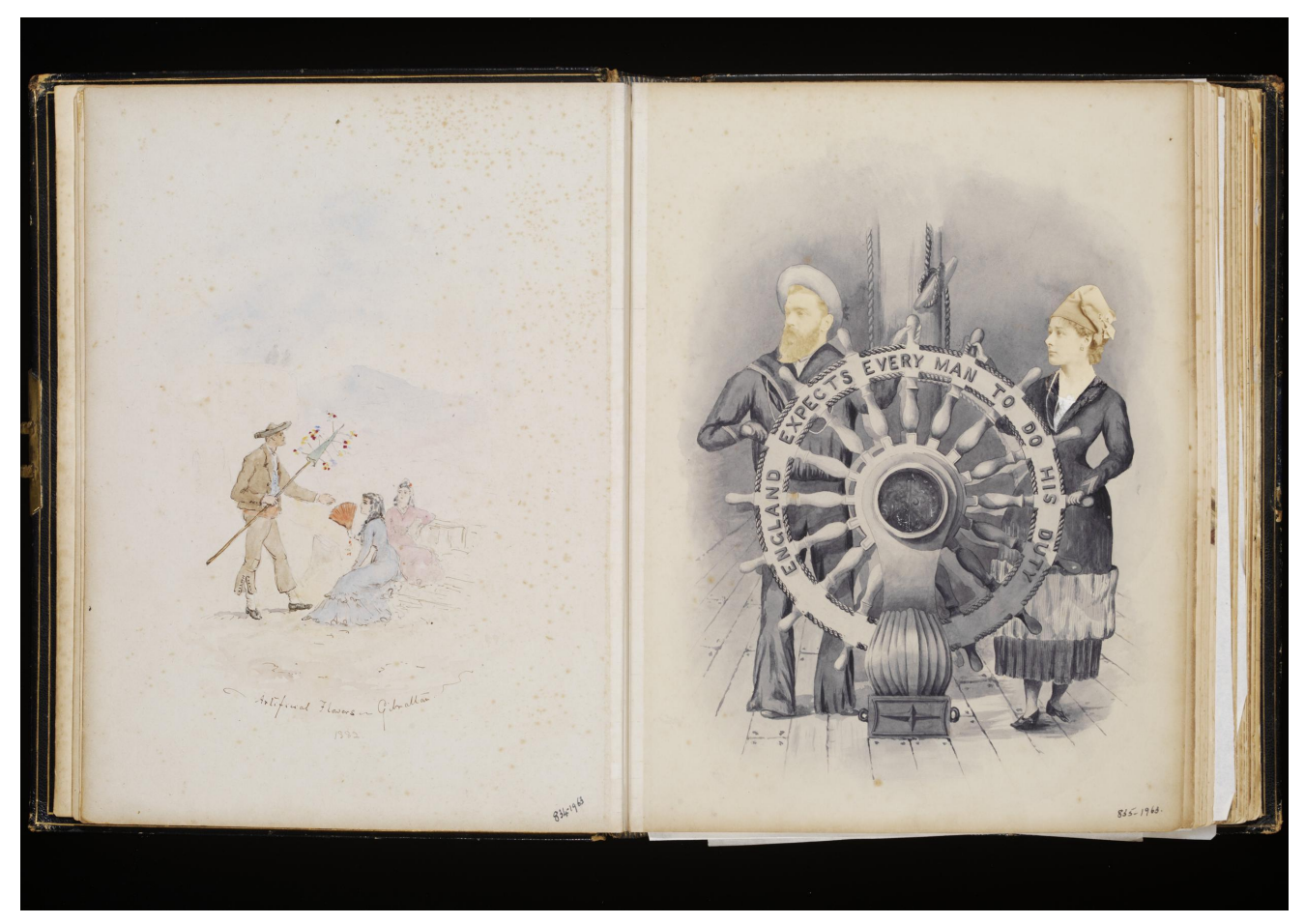

Figure 3.14 - Double-page spread of Artificial Flowers - Gibraltar (left) and England Expects Every Man to do His Duty (right) by Kate E. Gough, albumen print and watercolour, ca. 1870, 834-1963 and 835-1963. (C) Victoria and Albert Museum, London.

\footnotetext{
${ }^{93}$ Richard Palmer (Senior Web Developer at the V\&A), in conversation with the author, 9 March 2017.
} 
In comparison, the British Library possesses a wealth of digital assets for their internal purposes. These digital images of photographs and albums in particular have yet to be made available online, however, for copyright and web storage capacity reasons. While a copy of the digitized images is given to the client who requested the digitization, and the BL saves the RAW files for internal use, other public users cannot gain access to these files. The BL is intending to establish a technologically advanced and streamlined method in order to link these images to their corresponding records online in the near future. ${ }^{94}$ These examples at the V\&A and BL demonstrate that the technical capabilities of websites and DAM systems can also affect the method of digitization and have the potential of restricting the presentation of digital facsimiles online.

Even twenty years after the initial launch of Turning the Pages 1.0, a software created by Armadillo Systems in partnership with the British Library to animate the turning of a volume's pages, why are we still fixated on the replication of the analogue experience of a book? An interesting tension is created between the analogue and its digital counterpart when we attempt to translate physical experiences of an object, like texture and movement, to the digital. We simultaneously desire analogue experiences and qualities to be perfectly reproduced in a digital facsimile and criticize it for not being able to perform better or offer more features to help transcend the original experience of the object. While the digital facsimile may not be able to substitute this experience, digital tools offer other benefits like the opportunity to curate, annotate, and cross-analyze data and images. Therefore, digital tools are instrumental in the way they contribute to the process of research and interpretation of cultural heritage.

\footnotetext{
${ }^{94}$ John Falconer (Lead Curator of Prints, Drawings, and Photographs at the BL), in conversation with the author, 8 March 2017 


\section{$\underline{\text { Conclusion }}$}

In summary, the survey conducted at the Victoria and Albert Museum alongside the British Museum, the British Library, and the National Portrait Gallery reveals some of the intricacies involved in the approach to digitization of photographic albums including institutional factors. I had previously assumed that the organizational structure of photographs within the V\&A and NPG particularly signified the degree to which they were considered museum objects and subsequently influenced whether or not they were photographed for additional reproductive purposes. However, this proved not to be the case. If photographs and content of photographic albums was required for the purposes of exhibition, print sales, or publication, these objects would be shot regardless of their status within these institutions. I also learned that each institution follows digitization guidelines, like FADGI, as a frame of reference but every institution already has a standard of practice that has been shaped by their particular needs. For example, of the four institutions studied, while all are aware of colour management standards like Metamorfoze, only the NPG is actively and persistently striving to reach it. ${ }^{95}$

The variety of object types in each institution's collection impacts the kind of digital equipment they will possess and the kinds of digitization projects they will pursue. While the digitization of a museum's entire collection is always the utopian ideal, such overarching digitization plans are enormous in their scope in terms of time, number of objects, resources, staff, and budget, and, therefore, are not often feasible for an institution to maintain in the long-term. Each institution has a digitization plan of some scale, for example like the Factory Project at the V\&A for the Word and Image Department or like the digitization project pursued by the Prints and Drawings at the BM. At the BL, their type of collection

\footnotetext{
${ }^{95}$ Ed Lyon (Digitization Officer at the NPG), in conversation with the author, 25 April 2017.

Metamorfoze is a national program for the preservation of the paper heritage and is a collaboration between the National Library of the Netherlands and the National Archives. The Metamorfoze Preservation Imaging Guidelines is intended to be an image quality standard for two-dimensional materials. (van Dormolen, Metamorfoze Preservation Imaging Guidelines, accessed 5 July 2017)
} 
has resulted in the employment of high-resolution scanners in addition to cameras, and the division of technical staff to facilitate research reference scanning or digitization for publications.

On a practical level, I found that institutional practices like cataloguing and curatorial decisions also significantly control how and which elements of photographic albums are digitized. As discussed in Chapter Three, an album's cataloguing procedure at the V\&A and type of records created can directly affect the parts of the object that get described, recorded, and subsequently digitized, since these assets require a record to attach itself to. An album's cover was not previously digitized due to the lack of an existing object record for the digital asset to be associated to. As a digitization requirement for albums this is a rather new development in the last couple of years due to the increasing importance placed on contextual information.

I have noticed during my investigation that there is a growing understanding and desire to maintain an album's page border to offer contextual information when digitizing album photographs. While this is a recent and gradual development of the past few years, cropping is ultimately decided by the curator or client who requested the digitization job and there is generally not an obligatory standard. Each digitization project involving a photographic album can vary in its digitization process as, for example, in the case at the NPG with the Camille Silvy daybooks where the images were cropped and older museum object annotations digitally removed. Some may consider these markings to be a trace of institutional history and the object's history while under the ownership of the NPG, while others may see an outdated numbering system that does not reflect current ideas of 'best museum practice'. Although the removal of these annotations from the digital images may seem trivial, it is an example of how museums' documentation decisions shape our interpretation and experience of historical objects.

In that regard, the practicalities of digitizing photographic albums can only reach a certain degree of standardization because the way an album is photographed and edited is largely dictated by a curatorial 
vision. I have discovered that the base level of standardization is confined to an initial set-up (as addressed in Chapter Three as Method \#1) of an overhead camera, two opposing lights at a $45^{\circ}$ angle, and a foam wedge to prop up the volume. However, the needs of each album and its photographs are always different. This basic method is the most straightforward and was found to be common across all four institutions. I have learned that often the similarity in photographing methods is primarily dependent on the power of convention to gradually turn everyday tasks into an informal standard in each photographic studio. Photographers acquire an understanding of the optimal method to photograph different types of objects through their experiences with the artifacts and this was especially so during the early beginnings of the photographic studios like at the V\&A and BM. Access to an online culture has made the exchange of these experiences with other industry professionals easier and has helped to promote a broader community of sharing. It can be speculated that perhaps this community has contributed to a more recent degree of homogenization of practices across various museums' photographic studios.

Ultimately, this study cannot claim to be a complete representation of London-based institutional digitization approaches but does record some of the present methods practiced by major institutions to document albums in their collections. A key purpose of this thesis is to provide other cultural institutions with examples of currently common digitization methods for photographic albums. As technologies and methods are constantly evolving, ongoing research of digitization approaches to photographic albums is required. It will also be interesting for future researchers to consider how these practices have changed and continue to do so over time at different institutions.

To conclude, it is also important to note that this survey of significant cultural institutions' approaches to the digitization of photographic albums also points to the importance of studying documentation practices in museums as an essential but overlooked aspect of an institution's history. The current practices recorded here have implications that go beyond the technicalities of photographic 
digitization. They also inform us of how a museum makes decisions as it interprets and shapes cultural meaning for the public. 


\section{$\underline{\text { Appendices }}$}

\section{Appendix A}

The following questionnaire was created as a guideline to interview individuals from the photographic studios at the selected institutions. Appendix D offers the responses.

\section{Digitization Practices Questionnaire}

- Who are the main people responsible for processing a digitization request and at what stages?

- What is the object required to have (i.e. being fully catalogued, examined by conservation) prior to its digitization?

- What is the overall workflow?

- Handling of objects and different methods of photographing an album

- Environmental considerations

- Type of equipment used (camera/scanner/lighting)

- Metadata attribution

- File formats (master/access), resolution, bit depth, colour profile assignment

- How much of the page is included? (cropping/framing) Who decides?

- Condition of the object/conservation issue

- Are there certain guidelines that the Photo Studio adheres to? - if so how have these guidelines evolved?

- What are the primary and secondary purposes of digitization?

- How are these images presented?

- Is there an overarching digitization plan at the institution? - if so, are there anticipated changes coming in the near future?

- Are all albums automatically considered as candidates for online presentation? If not, are there any special documentation techniques used for those that are to be presented online? 


\section{Appendix B - Technical Guidelines for Bound Volumes and Prints and Photographs from FADGI}

These two charts are taken from the Federal Agencies Digitization Guidelines Initiative's "Technical

Guidelines for Digitizing Cultural Heritage Materials: Creation of Raster Image Files" to illustrate the inconsistency of specification for a photographic album, which bridges the two categories of 'Bound Volume' (page 19) and 'Prints and Photographs' (page 34).

\section{Bound Volumes: Rare and Special Materials}

Performance Level:

\begin{tabular}{|c|c|c|c|c|}
\hline & 1 Star & 2 Star & 3 Star & 4 Star \\
\hline Master File Format & & $\begin{array}{c}\text { TIFF, JPEG 2000, } \\
\text { PDF/A }\end{array}$ & $\begin{array}{c}\text { TIFF, JPEG 2000, } \\
\text { PDF/A }\end{array}$ & $\begin{array}{c}\text { TIFF, JPEG 2000, } \\
\text { PDF/A }\end{array}$ \\
\hline $\begin{array}{l}\text { Access File } \\
\text { Formats }\end{array}$ & & All & All & All \\
\hline Resolution & & $300 \mathrm{ppi}$ & $300 \mathrm{ppi}$ & $400 \mathrm{ppi}$ \\
\hline Bit Depth & & 8 & 8 or 16 & 16 \\
\hline Color Space & & $\begin{array}{l}\text { Adobe 1998, } \\
\text { ProPhoto, } \\
\text { ECIRGBv2 }\end{array}$ & $\begin{array}{l}\text { Adobe 1998, } \\
\text { ProPhoto, } \\
\text { ECIRGBv2 }\end{array}$ & $\begin{array}{l}\text { Adobe 1998, } \\
\text { ProPhoto, } \\
\text { ECIRGBv2 }\end{array}$ \\
\hline Color & & Color & Color & Color \\
\hline \multicolumn{5}{|c|}{ Measurement Parameters } \\
\hline $\begin{array}{l}\text { Tone Response } \\
\text { (OECF) } \\
\text { (Luminance) }\end{array}$ & & $\begin{array}{c} \pm 9 \text { count levels } \\
\leq 8\end{array}$ & $\begin{array}{c} \pm 6 \text { count levels } \\
\leq 5\end{array}$ & $\begin{array}{c} \pm 3 \text { count levels } \\
\leq 2\end{array}$ \\
\hline $\begin{array}{l}\text { White Balance } \\
\text { Error (Luminance) }\end{array}$ & & $\begin{array}{c} \pm 6 \text { counts levels } \\
\leq 6\end{array}$ & $\begin{array}{l} \pm 4 \text { count levels } \\
\leq 4\end{array}$ & $\begin{array}{c} \pm 3 \text { count levels } \\
\leq 2\end{array}$ \\
\hline $\begin{array}{l}\text { Illuminance Non- } \\
\text { Uniformity }\end{array}$ & & $<5 \%$ & $<3 \%$ & $<1 \%$ \\
\hline $\begin{array}{l}\text { Color Accuracy } \\
\text { (Mean } \Delta \mathrm{E} 2000)\end{array}$ & & $<8$ & $<5$ & $<3$ \\
\hline $\begin{array}{l}\text { Color Channel } \\
\text { Misregistration }\end{array}$ & & $<.80$ pixel & $<.50$ pixel & $<.33$ pixel \\
\hline MTF10 (10\% SFR) & & $\begin{array}{c}\text { sampling efficiency } \\
>70 \% \text { and SFR } \\
\text { response at half } \\
\text { sampling } \\
\text { frequency }<0.4\end{array}$ & $\begin{array}{c}\text { sampling efficiency } \\
>80 \% \text { and SFR } \\
\text { response at half } \\
\text { sampling } \\
\text { frequency }<0.3\end{array}$ & $\begin{array}{c}\text { sampling efficiency } \\
>90 \% \text { and SFR } \\
\text { response at half } \\
\text { sampling } \\
\text { frequency }<0.2\end{array}$ \\
\hline MTF50 (50\% SFR) & & $\begin{array}{l}50 \% \text { of half } \\
\text { sampling } \\
\text { frequency: } \\
{[25 \%, 85 \%]}\end{array}$ & $\begin{array}{l}50 \% \text { of half } \\
\text { sampling } \\
\text { frequency: } \\
{[35 \%, 75 \%]}\end{array}$ & $\begin{array}{l}50 \% \text { of half } \\
\text { sampling } \\
\text { frequency: } \\
{[45 \%, 65 \%]}\end{array}$ \\
\hline $\begin{array}{l}\text { Reproduction } \\
\text { Scale Accuracy }\end{array}$ & & $<+/-3 \%$ of AIM & $<+/-2 \%$ of AIM & $<+/-1 \%$ of AIM \\
\hline $\begin{array}{l}\text { Sharpening } \\
\text { (Maximum MTF) }\end{array}$ & & $<1.2$ & $<1.1$ & $<=1.0$ \\
\hline $\begin{array}{l}\text { Noise } \\
\Delta L^{*} \text { St. Dev } \\
\text { (Luminance) }\end{array}$ & & $\begin{array}{c}<5 \text { count levels } \\
<3\end{array}$ & $\begin{array}{c}<4 \text { count levels } \\
<2\end{array}$ & $\begin{array}{c}<3 \text { count levels } \\
<1\end{array}$ \\
\hline
\end{tabular}

Count values are expressed as 8 bit equivalents 
Prints and Photographs

Performance Level:

\begin{tabular}{|c|c|c|c|c|}
\hline & 1 Star & 2 Star & 3 Star & 4 Star \\
\hline Master File Format & TIFF & TIFF & TIFF & TIFF \\
\hline Access File Formats & All & All & All & All \\
\hline Resolution & 100 ppi & 200 ppi & 400 ppi & $600 \mathrm{ppi}^{1}$ \\
\hline Bit Depth & 8 & 8 & 8 or 16 & 16 \\
\hline Color Space & $\begin{array}{c}\text { Grey Gamma } 2.2 \\
\text { SRGB } \\
\text { Adobe } 1998 \\
\text { ProPhoto } \\
\text { ECIRGBv2 }\end{array}$ & $\begin{array}{c}\text { Grey Gamma } 2.2 \\
\text { SRGB } \\
\text { Adobe } 1998 \\
\text { ProPhoto } \\
\text { ECIRGBv2 }\end{array}$ & $\begin{array}{c}\text { Adobe } 1998 \\
\text { ProPhoto, } \\
\text { ECIRGBv2 }\end{array}$ & $\begin{array}{l}\text { Adobe } 1998 \\
\text { ProPhoto, } \\
\text { ECIRGBv2 }\end{array}$ \\
\hline Color & $\begin{array}{l}\text { Grayscale or } \\
\text { Color }\end{array}$ & $\begin{array}{l}\text { Grayscale or } \\
\text { Color }\end{array}$ & Color & Color \\
\hline \multicolumn{5}{|c|}{ Measurement Parameters } \\
\hline $\begin{array}{l}\text { Tone Response } \\
\text { (OECF) } \\
\text { (Luminance) }\end{array}$ & $\begin{array}{c} \pm 9 \text { count levels } \\
\leq 8\end{array}$ & $\begin{array}{c} \pm 7 \text { count levels } \\
\leq 6\end{array}$ & $\begin{array}{c} \pm 5 \text { count levels } \\
\leq 4\end{array}$ & $\begin{array}{c} \pm 3 \text { count levels } \\
\leq 2\end{array}$ \\
\hline $\begin{array}{l}\text { White Balance Error } \\
\text { (Luminance) }\end{array}$ & $\begin{array}{c} \pm 8 \text { counts } \\
\leq 8\end{array}$ & $\begin{array}{c} \pm 6 \text { counts } \\
\leq 6\end{array}$ & $\begin{array}{c} \pm 4 \text { count levels } \\
\leq 4\end{array}$ & $\begin{array}{c} \pm 3 \text { count levels } \\
\leq 2\end{array}$ \\
\hline $\begin{array}{l}\text { Illuminance Non- } \\
\text { Uniformity }\end{array}$ & $<8 \%$ & $<5 \%$ & $<3 \%$ & $<1 \%$ \\
\hline $\begin{array}{l}\text { Color Accuracy } \\
\text { (Mean } \Delta \mathrm{E} 2000)\end{array}$ & $<10$ & $<6$ & $<4$ & $<2$ \\
\hline $\begin{array}{l}\text { Color Channel } \\
\text { Misregistration }\end{array}$ & $<1.2$ pixel & $<.80$ pixel & $<.50$ pixel & $<.33$ pixel \\
\hline MTF10 (10\% SFR) & $\begin{array}{c}\text { sampling } \\
\text { efficiency }>60 \% \\
\text { and SFR } \\
\text { response at half } \\
\text { sampling } \\
\text { frequency }<0.4\end{array}$ & $\begin{array}{c}\text { sampling } \\
\text { efficiency }>70 \% \\
\text { and SFR } \\
\text { response at half } \\
\text { sampling } \\
\text { frequency }<0.4\end{array}$ & $\begin{array}{c}\text { sampling } \\
\text { efficiency }>80 \% \\
\text { and SFR } \\
\text { response at half } \\
\text { sampling } \\
\text { frequency }<0.3\end{array}$ & $\begin{array}{c}\text { sampling } \\
\text { efficiency }>90 \% \\
\text { and SFR } \\
\text { response at half } \\
\text { sampling } \\
\text { frequency }<0.2\end{array}$ \\
\hline MTF50 (50\% SFR) & $\begin{array}{c}50 \% \text { of half } \\
\text { sampling } \\
\text { frequency: } \\
{[25 \%, 95 \%]}\end{array}$ & $\begin{array}{c}50 \% \text { of half } \\
\text { sampling } \\
\text { frequency: } \\
{[30 \%, 85 \%]}\end{array}$ & $\begin{array}{l}50 \% \text { of half } \\
\text { sampling } \\
\text { frequency: } \\
{[35 \%, 75 \%]}\end{array}$ & $\begin{array}{l}50 \% \text { of half } \\
\text { sampling } \\
\text { frequency: } \\
{[40 \%, 65 \%]}\end{array}$ \\
\hline $\begin{array}{l}\text { Reproduction Scale } \\
\text { Accuracy }\end{array}$ & $<+/-3 \%$ of AIM & $<+/-3 \%$ of AIM & $<+/-2 \%$ of AIM & $<+/-1 \%$ of AIM \\
\hline $\begin{array}{l}\text { Sharpening } \\
\text { (Maximum MTF) }\end{array}$ & $<1.3$ & $<1.2$ & $<1.1$ & $<=1.0$ \\
\hline $\begin{array}{l}\text { Noise } \\
\Delta \mathrm{L}^{*} \text { St. Dev } \\
\text { (Luminance) }\end{array}$ & $\begin{array}{l}>6 \text { count levels } \\
<4\end{array}$ & $\begin{array}{l}>5 \text { count levels } \\
<3\end{array}$ & $\begin{array}{c}>4 \text { count levels } \\
<2\end{array}$ & $\begin{array}{l}>3 \text { count levels } \\
<1\end{array}$ \\
\hline
\end{tabular}

1. In rare cases, resolutions higher than 600 ppi may be needed to resolve fine details. 


\section{Appendix C - Resolutions for Photographic Print Material from the National Archives of the}

\section{Netherlands (Nationaal Archief)}

This chart was extracted from page 16 of "Digitisation of photographic material guidelines" published by the National Archives.

Table 1

Resolutions for photographic print material.

\begin{tabular}{|l|l|l|l|l|l|}
\hline From & Up to and including & Ppl \%] & \multicolumn{1}{l}{ Pixels/mm } & \multicolumn{1}{l|}{ [p/mm } & Efficiency \\
\hline $1.8 \times 2.4 \mathrm{~cm}$ & $513 \times 18 \mathrm{~cm}$ & & 600 & 23.6 & $11.890 \%$ \\
\hline $13 \times 18 \mathrm{~cm}$ & $518 \times 24 \mathrm{~cm}$ & 450 & 17.7 & 8.85 & $90 \%$ \\
\hline $18 \times 24 \mathrm{~cm}$ & $30 \times 42 \mathrm{~cm}$ & 300 & 11.8 & 5.9 & $90 \%$ \\
\hline Album pages etc. & Approx. $22 \times 34 \mathrm{~cm}$ & 450 & 17.7 & 8.85 & $90 \%$ \\
\hline
\end{tabular}

*) Only non-interpolated resolutions may be used. If the hardware makes this necessary, the next higher non-interpolated resolution should be used. For example 480 ppi instead of 450 ppi. 


\section{Appendix D - Technical Information About the Photographic Studios at Four London-based}

\section{Cultural Institutions}

The questionnaire given to selected cultural institutions (Appendix A) has resulted in this chart containing information about the museums' photographic studios, including their establishment date, physical environment, equipment and software, followed guidelines, and management of files.

\begin{tabular}{|c|c|c|c|c|c|}
\hline & $\begin{array}{l}\text { Victoria and } \\
\text { Albert Museum } \\
\text { Photographic } \\
\text { Studio } \\
\text { (3 Photo Studios) }\end{array}$ & $\begin{array}{l}\text { British } \\
\text { Museum } \\
\text { Photography } \\
\text { \& Imaging } \\
\text { Studio } \\
\text { (Publications } \\
\text { only) } \\
\text { (2 Photo } \\
\text { Studios) }\end{array}$ & $\begin{array}{l}\text { BM's } \\
\text { Departmenta } \\
\text { I Photo } \\
\text { Studios }\end{array}$ & $\begin{array}{l}\text { British } \\
\text { Library } \\
\\
\text { (2 Photo } \\
\text { Studios for } \\
\text { Internal \& } \\
\text { External } \\
\text { Clients) }\end{array}$ & $\begin{array}{l}\text { National } \\
\text { Portrait Gallery } \\
\text { (1 Photo Studio) }\end{array}$ \\
\hline $\begin{array}{l}\text { Date of } \\
\text { Establishment }\end{array}$ & 1853 & 1853 & 2007 & 1974 (approx.) & 2012 \\
\hline $\begin{array}{l}\text { Adoption of } \\
\text { digital } \\
\text { photography }\end{array}$ & $\begin{array}{l}\text { (1999, last project } \\
\text { in analogue } \\
\text { photography) } \\
2004 \text { (approx.) }\end{array}$ & $\begin{array}{l}2004 \text { (approx.) } \\
\text { (Prior to first } \\
\text { camera, } \\
\text { scanners were } \\
\text { used for } \\
\text { digitization) } \\
\end{array}$ & 2007 & 2006 (approx.) & $\begin{array}{l}2011 \\
\text { (Prior to 2011, } \\
\text { scanners were } \\
\text { used for } \\
\text { digitization) }\end{array}$ \\
\hline $\begin{array}{l}\text { Working } \\
\text { environment } \\
\text { colour }\end{array}$ & $\begin{array}{l}\text { Main Studio: light } \\
\text { grey walls } \\
\text { Henry Cole Photo } \\
\text { Studio: black } \\
\text { Blythe House } \\
\text { Studio: white }\end{array}$ & White walls & N/A & $\begin{array}{l}\text { Dark grey } \\
\text { walls with } \\
\text { black drapes }\end{array}$ & $\begin{array}{l}\text { Black walls with } \\
\text { anti-fatigue } \\
\text { flooring }\end{array}$ \\
\hline $\begin{array}{l}\text { Camera } \\
\text { equipment }\end{array}$ & $\begin{array}{l}\text { Hasselblad/Mamiya } \\
\text { analogue camera } \\
\text { with SINAR digital } \\
\text { backs } \\
\text { Copy stand and } \\
\text { tripod }\end{array}$ & $\begin{array}{l}\text { PhaseOne } \\
\text { camera and } \\
\text { digital back } \\
\text { Copy stand and } \\
\text { tripod }\end{array}$ & $\begin{array}{l}\text { Nikon D40 } \\
\text { Tripod or } \\
\text { handheld }\end{array}$ & $\begin{array}{l}\text { Mamiya } \\
\text { camera with } \\
\text { PhaseOne } \\
\text { digital back } \\
\text { Copy stand }\end{array}$ & $\begin{array}{l}\text { Hasselblad H4 } \\
\text { 200MS } \\
\text { Copy stand }\end{array}$ \\
\hline $\begin{array}{l}\text { Lighting } \\
\text { equipment }\end{array}$ & $\begin{array}{l}\text { Broncolor strobe } \\
\text { lighting, hanging } \\
\text { (Main Studio) and } \\
\text { standing system }\end{array}$ & $\begin{array}{l}\text { Ellinchrom } \\
\text { strobe lighting, } \\
\text { hanging system }\end{array}$ & $\begin{array}{l}2 \text { Ellinchrom } \\
\text { D-Lite flash } \\
\text { heads with } \\
\text { soft boxes }\end{array}$ & $\begin{array}{l}\text { Ellinchrom } \\
\text { strobe } \\
\text { lighting, on } \\
\text { stands }\end{array}$ & $\begin{array}{l}\text { Photon Beard } \\
\text { continuous } \\
\text { lighting }\end{array}$ \\
\hline
\end{tabular}




\begin{tabular}{|c|c|c|c|c|c|}
\hline $\begin{array}{l}\text { Computer } \\
\text { equipment }\end{array}$ & Macintosh & Macintosh & Windows PC & Macintosh & Macintosh \\
\hline $\begin{array}{l}\text { Capture } \\
\text { software }\end{array}$ & SINAR & CaptureOne & $\begin{array}{l}\text { In card } \\
\text { capture, no } \\
\text { live capture }\end{array}$ & CaptureOne & $\begin{array}{l}\text { Phocus } \\
\text { Hasselblad }\end{array}$ \\
\hline $\begin{array}{l}\text { Editing } \\
\text { software }\end{array}$ & Photoshop CS7 & Photoshop CS6 & - & $\begin{array}{l}\text { Photoshop } \\
\text { CS7 }\end{array}$ & Photoshop CS7 \\
\hline $\begin{array}{l}\text { Working } \\
\text { colour profile }\end{array}$ & Adobe 1998 & Adobe 1998 & - & Adobe 1998 & Adobe 1998 \\
\hline $\begin{array}{l}\text { Colour } \\
\text { management } \\
\text { guideline }\end{array}$ & $\begin{array}{l}\text { (aware of } \\
\text { Metamorfoze) }\end{array}$ & (FADGI) & - & ISO & Metamorfoze \\
\hline $\begin{array}{l}\text { Digitization } \\
\text { guidelines } \\
\text { followed }\end{array}$ & $\begin{array}{l}\text { Internally } \\
\text { established } \\
\text { (aware of FADGI) }\end{array}$ & $\begin{array}{l}\text { Internally } \\
\text { established } \\
\text { (aware of } \\
\text { FADGI) } \\
\end{array}$ & - & $\begin{array}{l}\text { Internally } \\
\text { established }\end{array}$ & $\begin{array}{l}\text { Internally } \\
\text { established }\end{array}$ \\
\hline $\begin{array}{l}\text { Master File: } \\
\text { format and } \\
\text { min. size } \\
\text { standard }\end{array}$ & $\begin{array}{l}\text { Edited TIFFs } \\
133 \text { megabytes }\end{array}$ & $\begin{array}{l}\text { Edited TIFFs } \\
50 \text { megabytes }\end{array}$ & JPEGs & $\begin{array}{l}\text { RAW files } \\
100 \\
\text { megabytes }\end{array}$ & $\begin{array}{l}\text { Edited TIFFs } \\
22 \text { megabytes }\end{array}$ \\
\hline
\end{tabular}




\section{Appendix E - Case Study of the Digitization of a Guardbook at the Victoria \& Albert Museum}

A case study was performed at Blythe House Archives with the assistance of V\&A Photographic

Technician, Charlotte Hazeldine. A guardbook (archive reference number MA/32/237) that is housed in

the Archives of Art and Design was used as an example of how the V\&A digitizes a photographic album.

A SINAR digital back with a medium-format Hasselblad camera and an $18 \mathrm{~mm}$ lens was used, shooting at the optimum for the lens at $\mathrm{f} / 11.5$. The two Broncolor strobes are positioned on opposite sides at a $45^{\circ}$ angle.

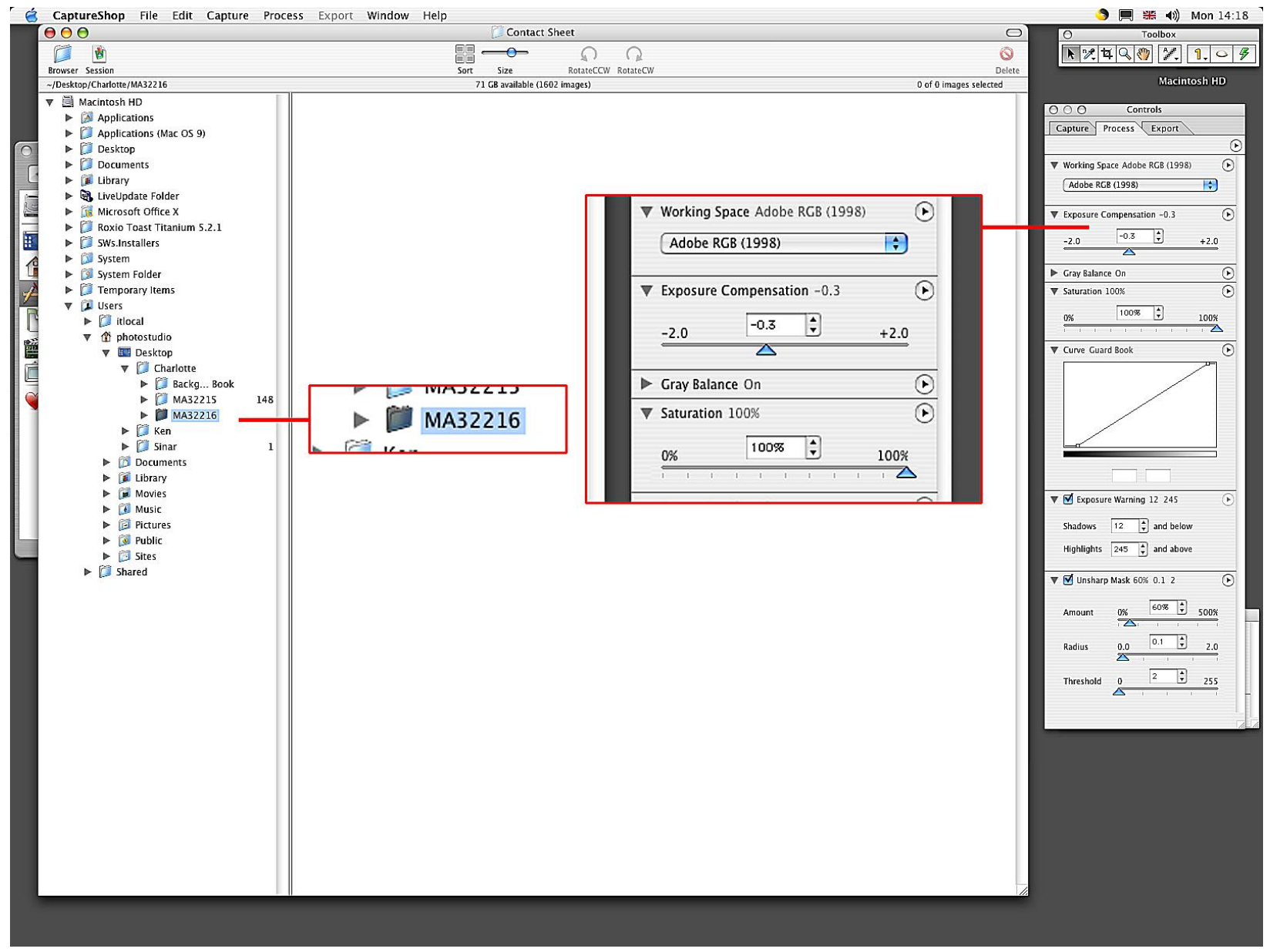

Step 1 - A new folder with the guardbook's reference number is created in CaptureShop which is the capture software for the camera (MA/32/237). The capture settings are fixed at Adobe 1998 as the working colour space and -0.3 exposure compensation. Screen capture by the author. 


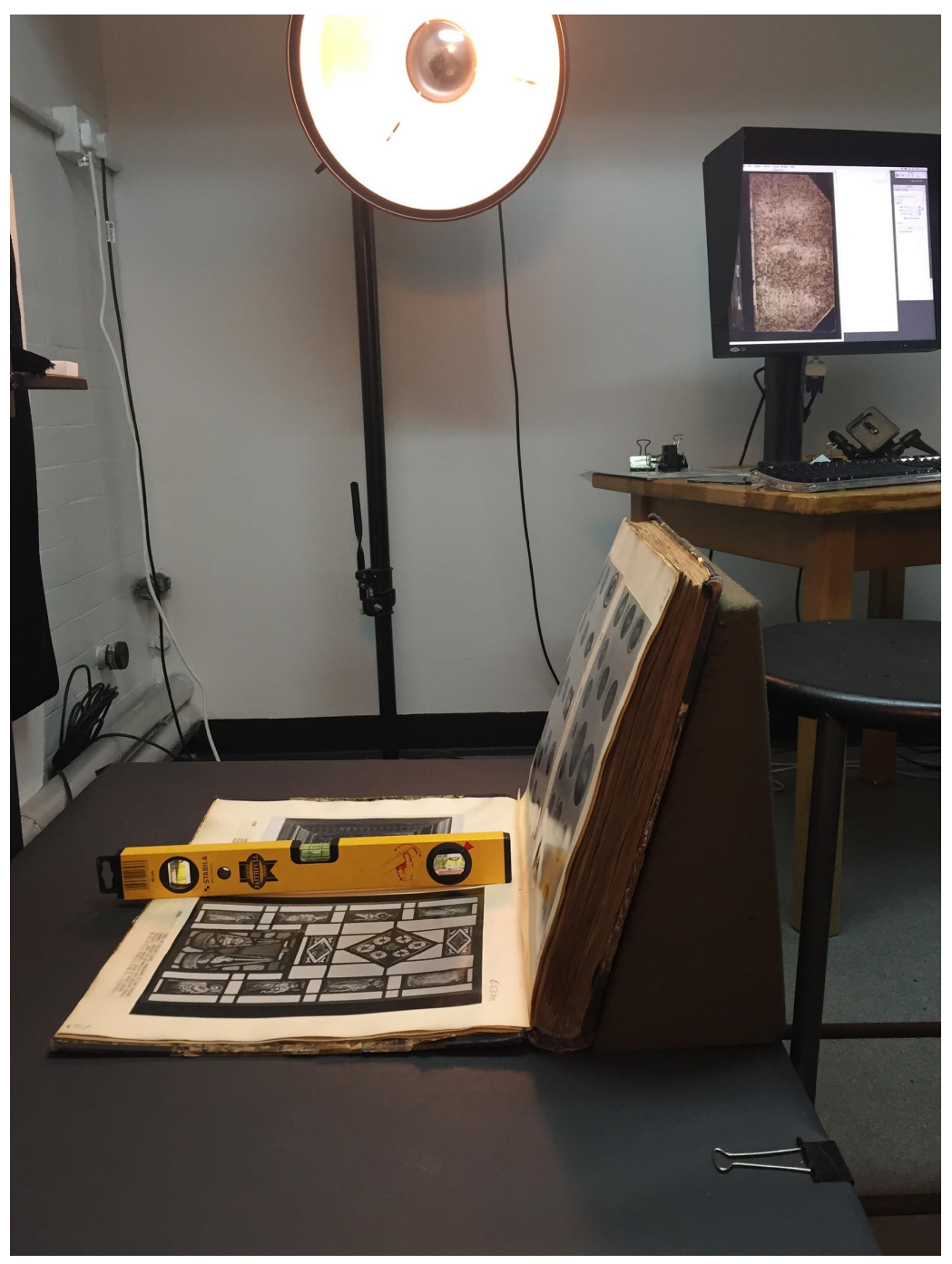

Step 2 - The guardbook is placed onto the platform and is held in place at $90^{\circ}$ by a foam wedge. The volume's right hand pages are photographed first, from the last page to the first page. It is done in this sequence because flipping the pages downwards is easier than upwards. A level is used before shooting to ensure the album is on a flat plane. The covers of the guardbooks are often distorted from wear over the years and a level plane is necessary to maintain a consistent and focused image. Photography by the author. 


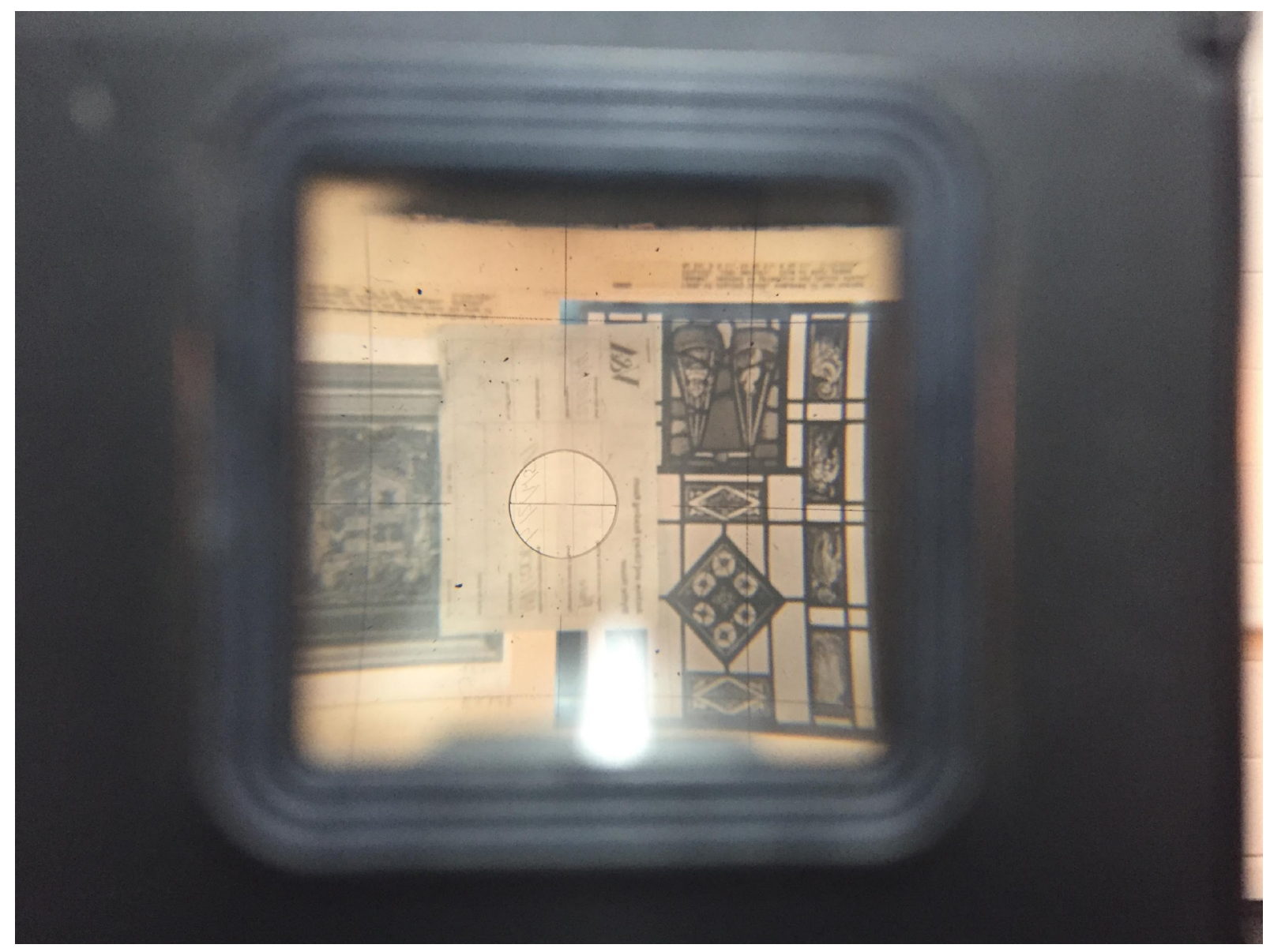

Step 3 - The camera's focused is checked using a piece of paper containing straight lines. The lines will conjoin to indicate that it is in focus. Focus is checked every 15 pages as the increased and decreased thickness of the pages changes the plane of focus. Photography by author. 

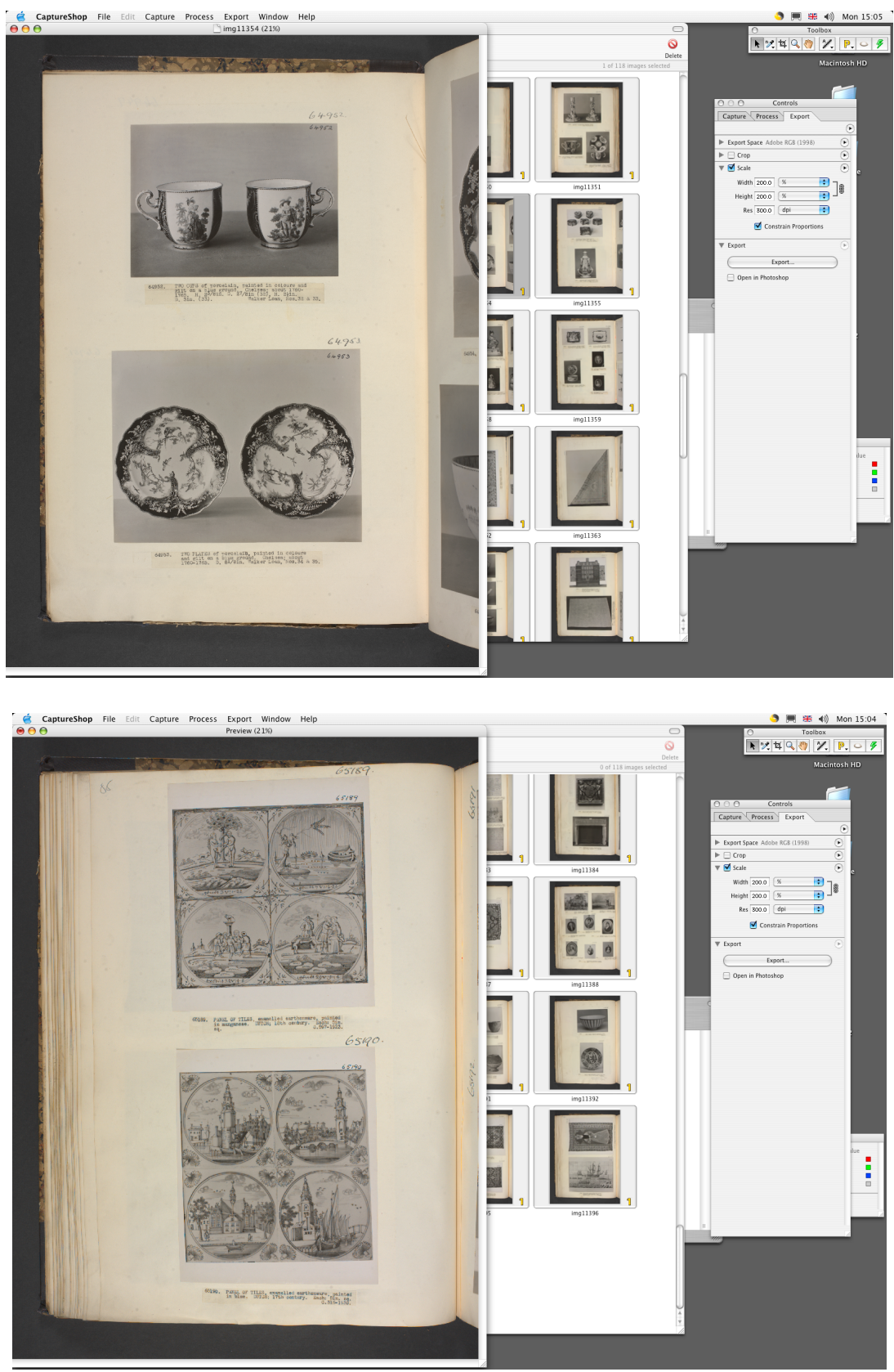

Step 4 - A preview shot is taken to ensure that the album is in the centre of the image. It is important to keep the photographs in the guardbook straight, to anticipate the movement of the book and shifting of the pages within the frame as you digitize the album, and to preserve some of the gutter and opposing page in the shot. As you flip through the guardbook, the pages do not always stay in the same place perhaps due to the way the album has been bound. Screen captures by the author. 


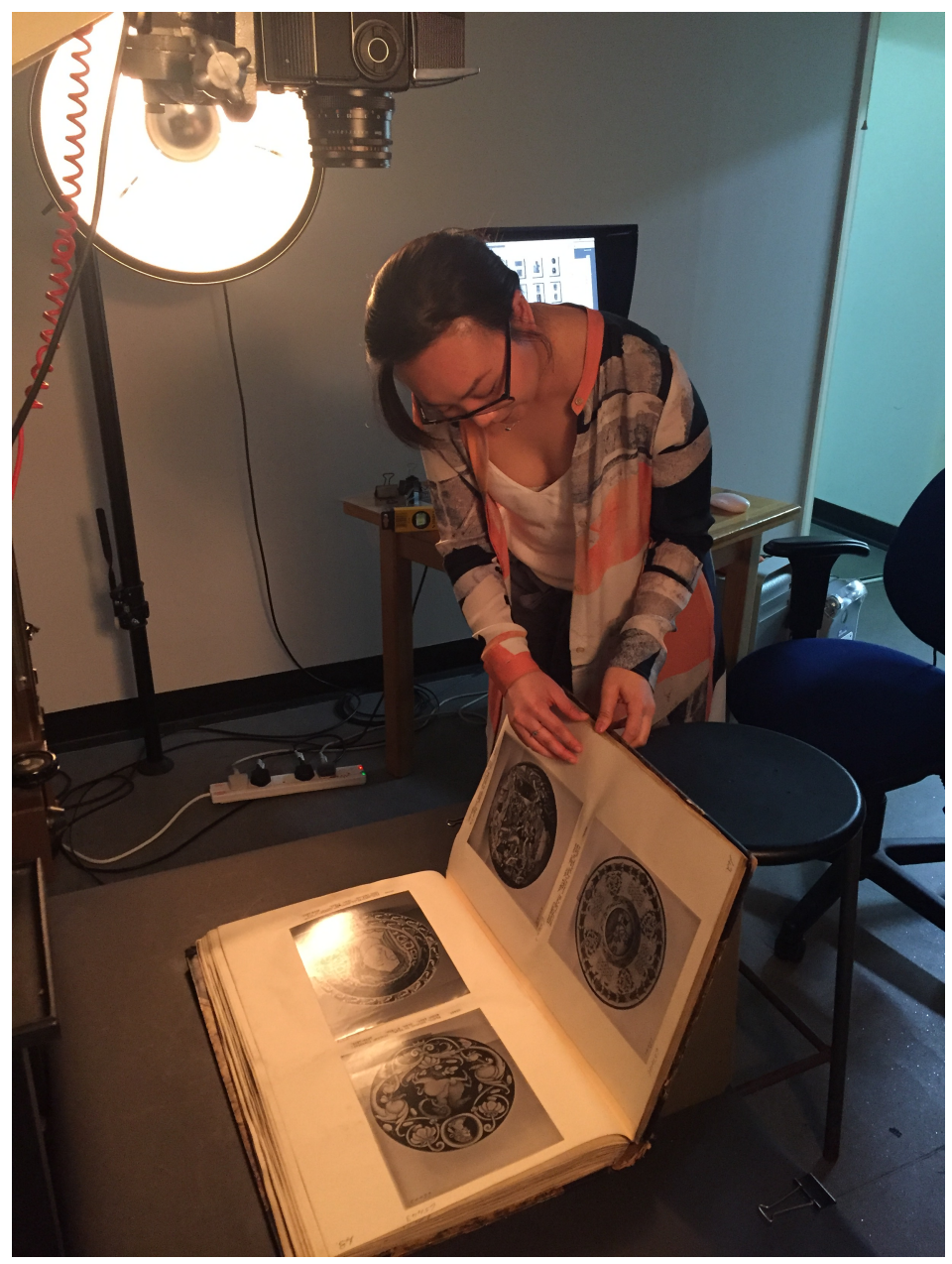

Step 5 - After the right hand pages are photographed, the guardbook is then reversed and the left hand pages are digitized. The front and back covers are also digitized. Photography by Charlotte Hazeldine.

Step 6 - The RAW (.sti) files produced by the camera in CaptureShop are then exported at 200\% as 8-bit colour 300dpi TIFFs. 


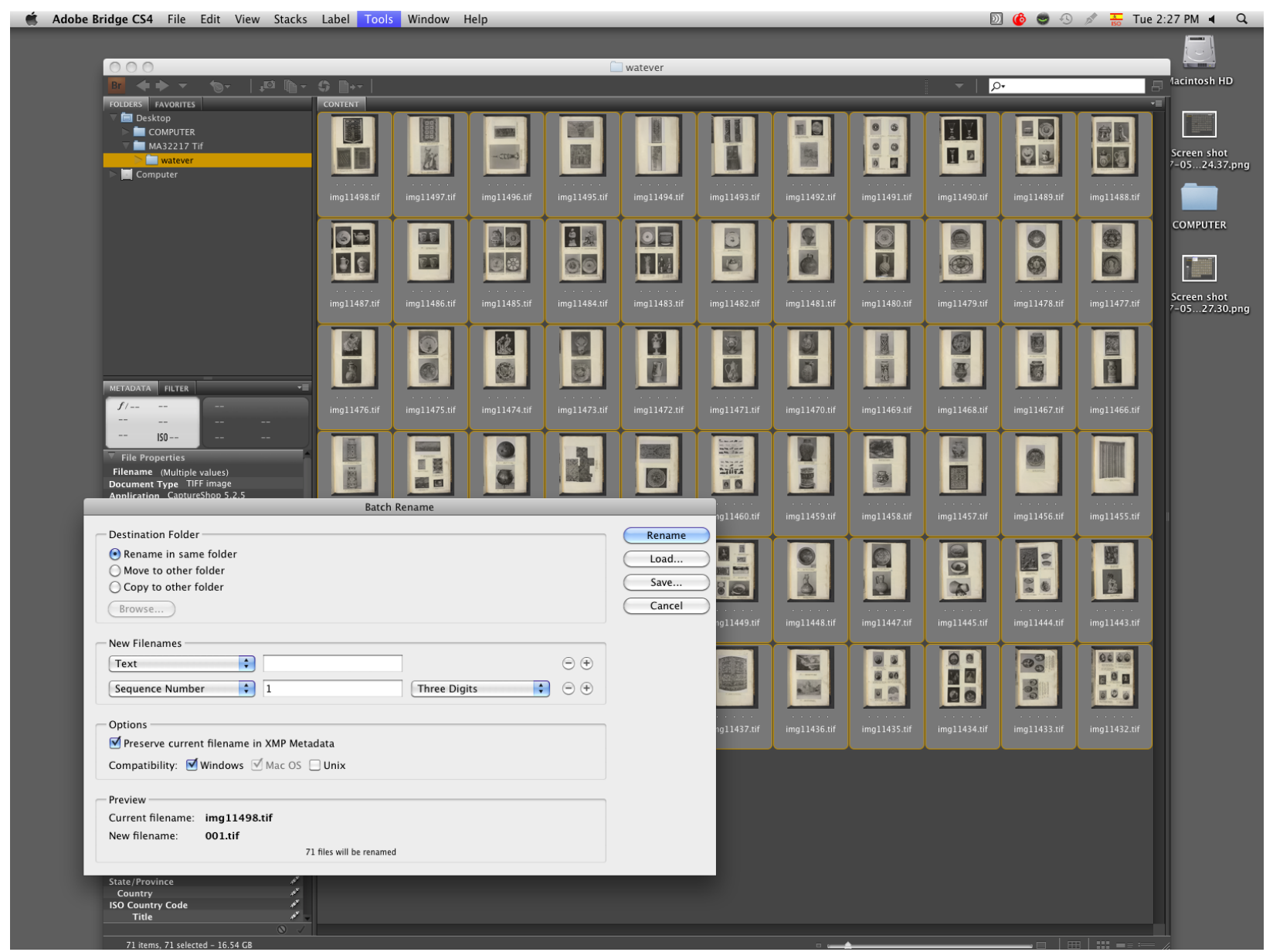

Step 7 - Once the files are exported, the TIFFs are then opened in Adobe Bridge to sequence and then rename. A temporary folder is made and the images of the right-hand side pages are moved into it. A 'batch rename' is performed by Bridge to rename all the files in sequence. Screen capture by the author. 


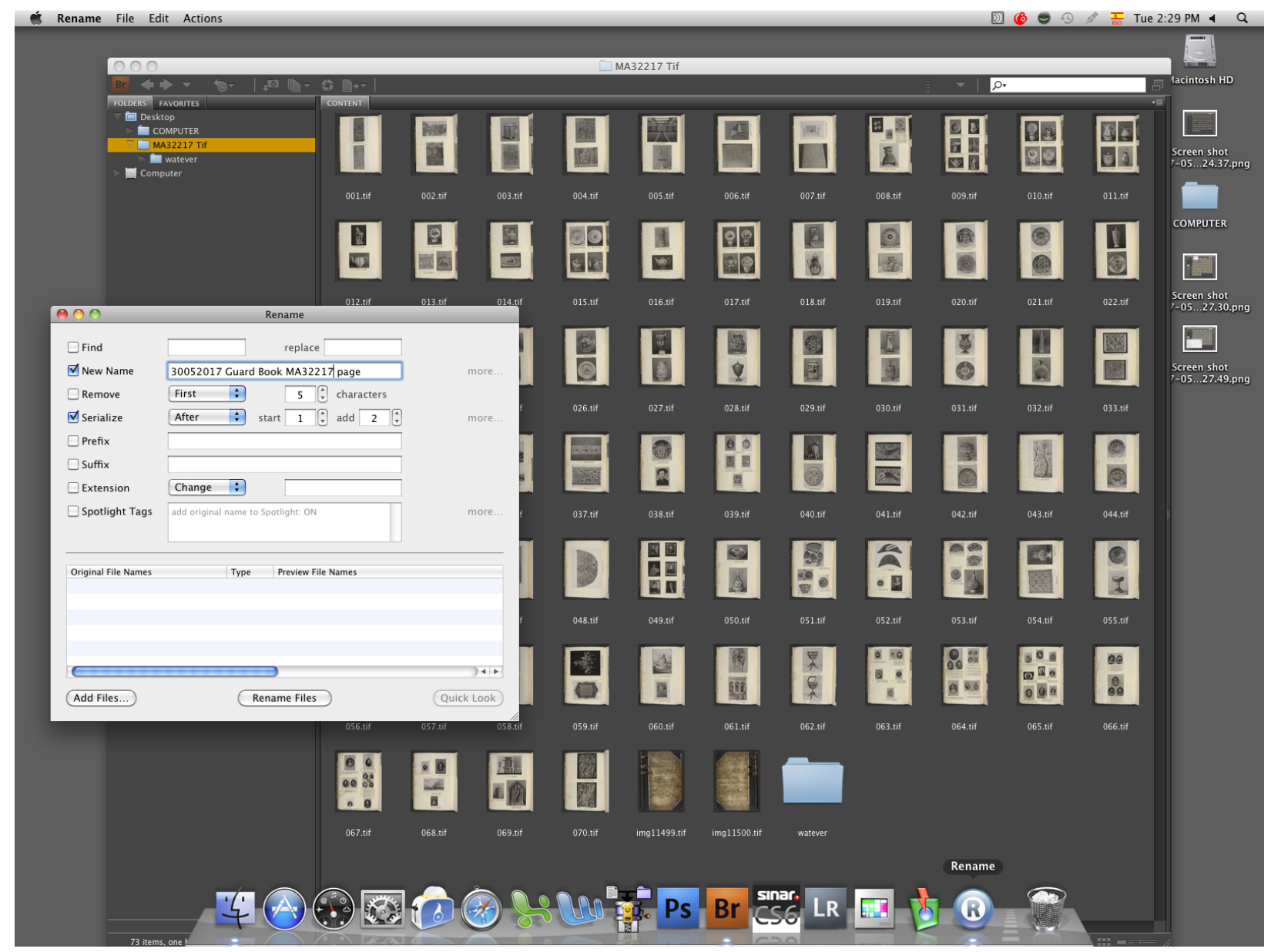

Step 8 - After all the files have been renamed in order, the two groups of images (right hand side and left hand side pages) will need to be merged together to form the correct sequence of the album. An application called 'Rename' is used to do this. All files are retitled to: 'Date' Guard Book 'MA Reference Number' 'page x' (30052017 Guard Book MA32217 page x). One group of files are uploaded into this program and it is able to rename files consecutively in an odd and even sequence. Screen capture by the author. 


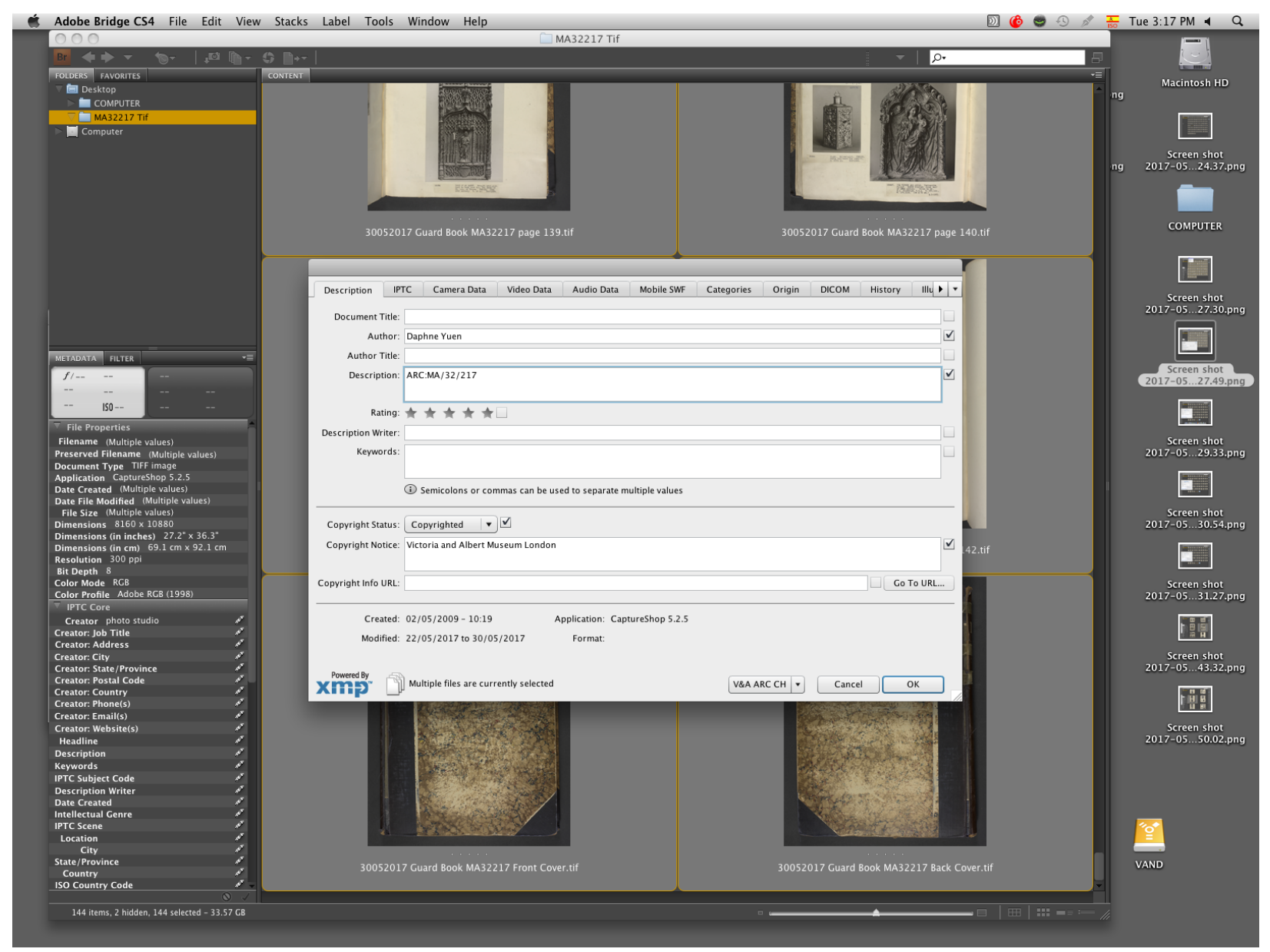

Step 9 - Next, the files are embedded with metadata including the photographer's name, the guardbook reference number, and date. Screen capture by the author. 


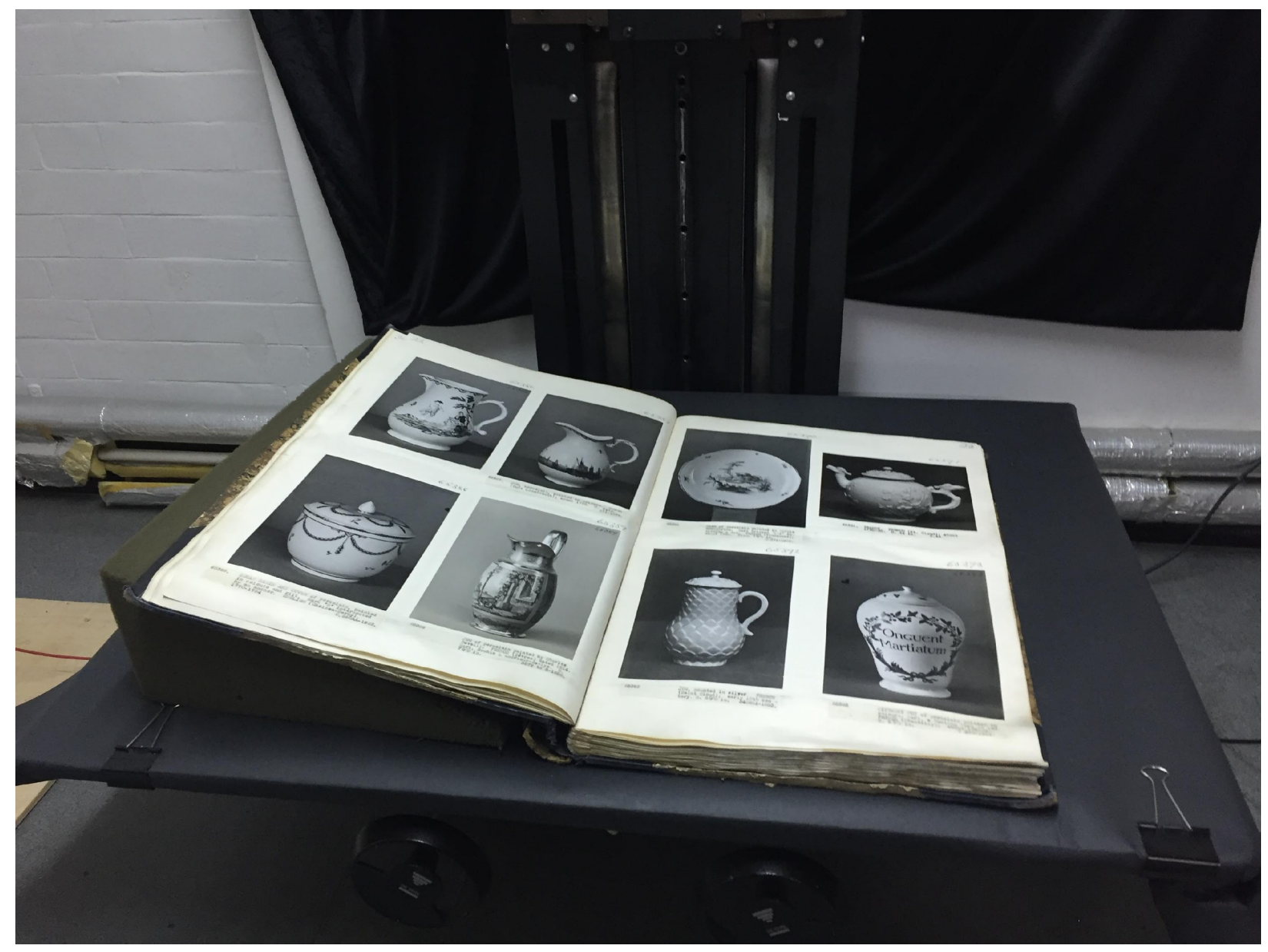

Step 10 - After the images have been renamed and sequenced, the files are cross-checked with the pages of the guardbook in order to check that no pages have been missed in the digitization process. Photography by author. 


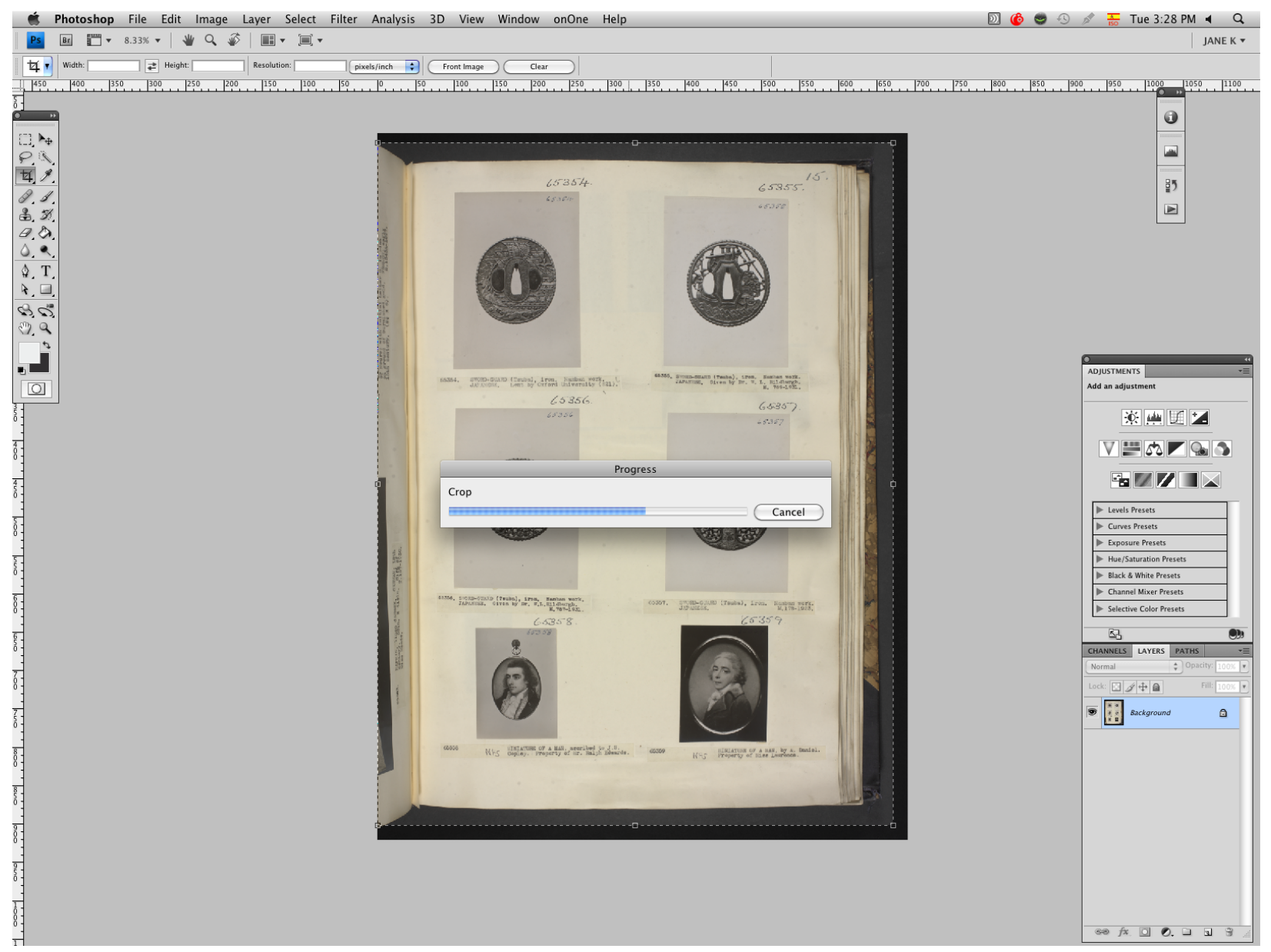

Step 11 - The images are then cropped and straightened if need be (according to the pasted photographs on the page). Screen capture by the author.

Step 12 - The files are then ready to be ingested in the V\&A's Digital Asset Management System, VADAR. 


\section{Bibliography}

\section{On the History of the Photographic Album and its Preservation Issues}

Bann, Stephen, ed. Art and the Early Photographic Album. New Haven: Yale University Press, 2011.

Clarke, Bryan. "The Imperfect Image: Photographs their Past, Present, and Future: Some Observations on the Development of Albums Containing Photographs and Aspects of their Deterioration." Paper presented at the Centre for Photographic Conservation, Cumbria, UK, April 6-10, 1992.

Curtis, Verna Posever. Photographic Memory: The Album in the Age of Photography. New York: Aperture Foundation, 2011.

Dahlgren, Anna. "Dated Photographs: The Personal Photo Album as Visual and Textual Medium." Photography and Culture 3, no. 2 (2010): 175-194.

Haworth-Booth Mark. "Camille Silvy: The Photography of Works of Art as Record and Restoration" in Bann, Art and the Early Photographic Album. New Haven: Yale University Press, 2011. 81-88.

Helfand, Jessica. Scrapbooks: An American History. New Haven: Yale University Press, 2008.

Kunard, Andrea. "Traditions of Collecting and Remembering: Gender, class and the nineteenth-century sentiment album and photographic album" Early Popular Visual Culture 4, no. 3 (2006): 227-243.

Langford, Martha, and Musée McCord d'histoire canadienne. Suspended Conversations: The Afterlife of Memory in Photographic Albums. Montreal; Kingston: McGill-Queen's University Press, 2001.

Parr, Martin and Gerry Badger. The Photobook: A History - Volume I. London; New York: Phaidon Press, 2004.

Rutherston, Jane. "Victorian Album Structures." Master's thesis, Victoria and Albert Museum, London, 1996. Unpublished.

Sandbye, Mette. "Looking at the family photo album: a resumed theoretical discussion of why and how." Journal of Aesthetics \& Culture 6, no. 1 (2014): 1-17.

Siegel, Elizabeth. Playing with Pictures: The Art of Victorian Photocollage. Chicago: Art Institute of Chicago and Yale University Press, 2009.

Taft, Robert. Photography and the American Scene - A Social History 1839-1889. New York: Dover Publications, 1938.

Welling, William. Collector's Guide to Nineteenth Century Photographs. New York: Macmillan Publishing Co. Inc., 1976 


\section{On Digitization's Impact on Object Materiality and Relationship with Historical Objects}

Cameron Fiona. "Beyond the Cult of the Replicant: Museums and Historical Digital Objects - Traditional Concerns, New Discourses" in Cameron and Kenderdine, Theorizing Digital Cultural Heritage, 49-70.

Cameron, Fiona, and Sarah Kenderdine, eds. Theorizing Digital Cultural Heritage: A Critical Discourse. Cambridge: MIT Press, 2007.

Edwards, Elizabeth, and Janice Hart, eds. Photographs, Objects, Histories - Introduction. Florence, US: Routledge, 2004. Accessed 10 April 2016. ProQuest ebrary.

Kuan, Christine. "7 Lessons Learned for Digital Culture" in Wu and Din, Digital Heritage and Culture: Strategy and Implementation. 41-52.

Lin, James Quo-Ping. "IT-Enabled Innovative Services as a Museum Strategy: Experience of the National Palace Museum, Taipei, Taiwan" in Wu and Din, Digital Heritage and Culture: Strategy and Implementation, 3-20.

Newell, Jenny. "Old Objects, New Media: Historical Collections, Digitization and Affect" Journal of Material Culture 17, no. 3 (2012): 287-306.

Parry, Ross. Museum in the Digital Age. New York: Routledge. 2010.

Sassoon, Joanna. "Photographic Materiality in the Age of Digital Reproduction" in Edwards and Hart, Photographs, Objects, Histories. 196-213.

Savedoff, Barbara. Transforming Images: How Photography Complicates the Picture. Ithaca, London: Cornell University Press, 2000.

Volpe, Andrea L. "Archival meaning: Materiality, digitization, and the nineteenth-century photograph. Afterimage 36, no. 6 (2009): 11.

Wu, Steven and Herminia Din, eds. Digital Heritage and Culture: Strategy and Implementation. New Jersey: World Scientific, 2015. 


\section{Digitization Guidelines and Standards for Photographic Albums}

Berendse, Martin. "Digitisation of Photographic Materials." Nationaal Archief-Images for the Future, last modified September 2010.

http://en.nationaalarchief.nl/sites/default/files/docs/guidelines_digitisation_photographic_material s_0.pdf

Besser, Howard. "Introduction to Imaging - Revised Edition." The Getty. Edited by Sally Hubbard and Deborah Lenert. Accessed 13 Feb 2017.

http://www.getty.edu/research/publications/electronic_publications/introimages/intro.html

"City of Toronto Archives Digitization Program." City of Toronto Archives. Accessed 13 Feb 2017. https://www.eloquent-systems.com/download/City_of_Toronto_Archives_-

_Digitization_Program.pdf

Conway, Paul. "Preservation in the age of google: Digitization, digital preservation, and

dilemmas." The Library Quarterly: Information, Community, Policy 80, no. 1 (2010): 61-79.

Corrado, Edward M. and Heather Lea Moulaison. Digital Preservation for Libraries, Archives, and Museums. Maryland: Rowman \& Littlefield, 2014.

Hand, Martin. Making Digital Cultures: Access, Interactivity, and Authenticity. Abingdon, GB: Routledge. Accessed October 16, 2016. ProQuest ebrary.

"Preservation - Still and Aerial Photographs." U. S. National Archives and Records Administration. Accessed 13 Feb 2017. https:/www.archives.gov/preservation/products/definitions/photodef.html

Rieger, Thomas. "Technical Guidelines for Digitizing Cultural Heritage Materials: Creation of Raster Image Files." Federal Agencies Digitization Guidelines Initiative, last modified September 2016. http://www.digitizationguidelines.gov/guidelines/FADGI_Still_Image_Tech_Guidelines_2016.pdf

World Digital Library, "World Digital Library - Digital Image Standards" Accessed 13 Feb 2017, http://project.wdl.org/standards/imagestandards.html 


\section{Additional Sources}

"Albums of Photographs, 1850-present" The Library of Congress - Prints \& Photographs Reading Room. last modified December 2010, https://www.loc.gov/rr/print/coll/photoalbums.html

Association for Historical and Fine Art Photography, accessed April 30, 2017. http://www.ahfap.org.uk/

Benjamin, Walter. "The Work of Art in the Age of Mechanical Reproduction" in Illuminations, edited by Hannah Arendt, translated by Harry Zohn. New York: Schocken Books, 1969.

Date, Christopher, and Anthony Hamber. "The Origins of Photography at the British Museum, 18391860.” History of Photography 14, no. 4 (1990): 309-25.

Desvallées, André, and François Mairesse, eds. ICOM - Key Concepts of Museology. Paris: Armand Colin, 2010.

Dodds, Douglas and Ella Ravilious. "The Factory Project: digitisation at the Victoria and Albert Museum” Art Libraries Journal 34, no. 2. (2009): 10-17.

Dormolen, Hans van. Metamorfoze Preservation Imaging Guidelines. Accessed 5 July 2017, https://www.metamorfoze.nl/sites/metamorfoze.nl/files/publicatie_documenten/Metamorfoze_Pre servation_Imaging_Guidelines_1.0.pdf

"Getty Art and Architecture Thesaurus Online" Getty Research Institute. Accessed 1 June 2017, http://www.getty.edu/vow/AATFullDisplay?find $=$ cockling\&logic $=$ AND\&note $=\&$ english $=$ N\&pre v_page $=1 \&$ subjectid $=300228335$

“About IIIF” International Image Interoperability Framework. Accessed 10 Aug 2017, http://iiif.io/about/

“Image Permanence Institute Glossary” Image Permanence Institute. Accessed 1 June 2017, https://www.imagepermanenceinstitute.org/resources/glossary\#S

"Introduction to the Primary Collection" National Portrait Gallery. Accessed 1 June 2017. http://www.npg.org.uk/collections/about/primary-collection/learn-more-primary

"Search the Collection - Camille Silvy" National Portrait Gallery. Accessed 1 June 2017, http://www.npg.org.uk/collections/search/person/mp08115/camille-silvy

Wang, Helen and John Perkins, eds. Handbook to the Collections of Sir Aurel Stein in the UK. London: The British Museum, 2008. 